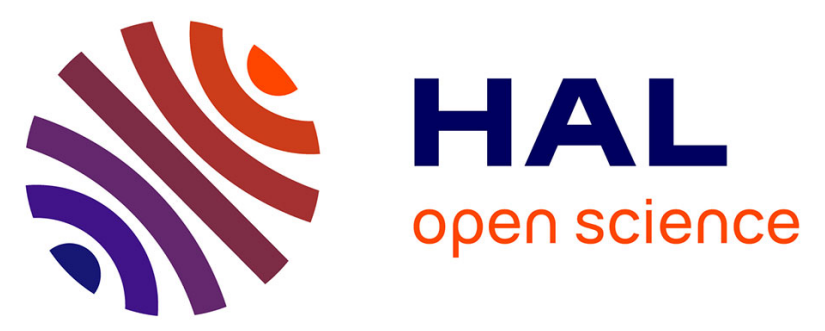

\title{
Processes controlling silicon isotopic fractionation in a forested tropical watershed: Mule hole critical zone observatory (Southern India)
}

Jean Riotte, Jean-Dominique Meunier, Thomas Zambardi, Stephane Audry, Doris Barboni, Krishnamurthy Anupama, Srinivasan Prasad, Jérôme

Chmeleff, Franck Poitrasson, Muddu Sekhar, et al.

\section{To cite this version:}

Jean Riotte, Jean-Dominique Meunier, Thomas Zambardi, Stephane Audry, Doris Barboni, et al.. Processes controlling silicon isotopic fractionation in a forested tropical watershed: Mule hole critical zone observatory (Southern India). Geochimica et Cosmochimica Acta, 2018, 228, pp.301 - 319. 10.1016/j.gca.2018.02.046 . hal-01914248

\section{HAL Id: hal-01914248 \\ https://hal-amu.archives-ouvertes.fr/hal-01914248}

Submitted on 29 Mar 2019

HAL is a multi-disciplinary open access archive for the deposit and dissemination of scientific research documents, whether they are published or not. The documents may come from teaching and research institutions in France or abroad, or from public or private research centers.
L'archive ouverte pluridisciplinaire HAL, est destinée au dépôt et à la diffusion de documents scientifiques de niveau recherche, publiés ou non, émanant des établissements d'enseignement et de recherche français ou étrangers, des laboratoires publics ou privés. 


\title{
Processes controlling silicon isotopic fractionation in a forested tropical watershed: Mule Hole Critical Zone Observatory (Southern India)
}

Jean Riotte ${ }^{1,2^{*}}$, Jean-Dominique Meunier ${ }^{3}$, Thomas Zambardi ${ }^{1}$, Stéphane Audry ${ }^{1}$, Doris Barboni ${ }^{3}$, Krishnamurthy Anupama ${ }^{4}$, Srinivasan Prasad $^{4}$, Jérôme Chmeleff ${ }^{1}$, Franck Poitrasson $^{1}$, Muddu Sekhar ${ }^{2,5}$, Jean-Jacques Braun ${ }^{1}$

(*) Corresponding author: jean.riotte@ird.fr

1- Géosciences Environnement Toulouse (Université Paul-Sabatier, IRD, CNRS), 14 avenue E. Belin, 31400 Toulouse, France

2- Indo-French Cell for Water Sciences, IRD-Indian Institute of Science, Bangalore 560012 India

3- Aix Marseille Univ, CNRS, IRD, Coll France, CEREGE, 13545 Aix-en-Provence cedex 04, France

4- French Institute of Pondicherry PB 33, UMIFRE 21 CNRS-MAEE / USR 3330, Pondicherry 605001 India

5- Civil Engineering Department, Indian Institute of Science, Bangalore 560012 India

\begin{abstract}
Assessing the dynamics of the silica cycle in the critical zone remains challenging, particularly within the soil, where multiple processes are involved. To improve our understanding of this cycle in the Tropics, and more specifically the role played by vegetation, we combined elemental Si mass balance with the $\delta^{30} \mathrm{Si}$ signatures of the compartments involved in the water-plant-rock interactions of a tropical forested watershed, Mule Hole (Southern India). To accomplish this, we analysed (1) the $\delta^{30} \mathrm{Si}$ values of presentday litter phytoliths from tree leaves and grass, as well as soil amorphous silica (ASi); (2) the $\mathrm{Si}$ isotope fractionation induced by phytolith dissolution; (3) the silicon mass balance inferred from isotopes at the soil-plant scale; and (4) the consistency between water sources and the $\delta^{30} \mathrm{Si}$ signatures in the ephemeral stream.

The $\delta^{30} \mathrm{Si}$ values of present-day litter phytoliths and soil ASi vary within a narrow range of 1.10 to $1.40 \%$ for all samples, but two deep vertisol samples which likely trapped phytoliths from different vegetation growing under more humid conditions, as indicated by pollen analysis. A homogeneous signature of litter is a minimum condition for using $\delta^{30} \mathrm{Si}$ as a
\end{abstract}


proxy for the litter/phytolith source of $\mathrm{Si}$. However, litter-ash dissolution experiments demonstrate that the incipient dissolution of phytoliths fractionates $\mathrm{Si}$ isotopes, with the preferential dissolution of ${ }^{28} \mathrm{Si}$ over ${ }^{30} \mathrm{Si}$ yielding $\delta^{30} \mathrm{Si}$ values as low as $-1.41 \%$. Values close to the whole-sample signatures, i.e., above $1 \%$, were recovered in the solution after a few hours of water-ash interaction. At the soil-plant scale, the average $\delta^{30} \mathrm{Si}$ value of soilinfiltrating solutions is slightly lighter than the average phytolith signature, which suggests phytoliths as the source of soil dissolved Si. The isotopic budget of dissolved Si within the soil layer, which was obtained based on previous elemental fluxes, is imbalanced. Equilibrating the isotopic budget would imply that up to $4100 \mathrm{~mol} \mathrm{ha}^{-1} \mathrm{yr}^{-1}$ of silica is taken up by vegetation, which is almost twice as large as that initially estimated from the elemental budget. The additional Si flux taken up, and likely stored in woody stems, was estimated assuming that $\mathrm{Si}$ isotopes followed a steady-state model for the whole Si plant uptake and then followed a Rayleigh model once in the plants. The $\delta^{30} \mathrm{Si}$ value of the additional Si flux taken up should be close to $0 \%$, i.e., enriched in light $\mathrm{Si}$ isotopes compared to the litter. If steady-state conditions apply, the source could correspond to soil ASi dissolution or deep (saprolite) root uptake. At the outlet of the watershed, the stream exhibits low $\delta^{30} \mathrm{Si}$ values (0.28 to $0.71 \%$ ) during peak flows and high $\delta^{30} \mathrm{Si}$ values $(1.29$ to $1.61 \%$ ) during the recessions at the end of the rainy season. Heavy $\delta^{30} \mathrm{Si}$ signatures are consistent with the expected domination of seepage at the end of floods. The light $\delta^{30} \mathrm{Si}$ values during peak flow are slightly lower than the overland flow signature and reflect either a sampling bias of overland flow or a minor but significant contribution of another Si source within the stream, possibly the partial dissolution of phytoliths from the suspended load, with slight isotopic fractionation. This study confirms that vegetation controls the silicon cycle in this dry tropical forest. It also shows that silicon isotopes yield a better grasp of the mass balance and sources and potential mechanisms involved than the consideration of only silicon concentrations. However, this proxy still relies on working hypotheses, notably steady-state and/or Rayleigh fractionation models, which need to be confirmed in further studies.

\section{Introduction}

The biological cycle of silicon has received increasing attention in the last decade because it mobilizes large amounts of silica, particularly in the Tropics, where rivers contribute $74 \%$ of the dissolved flux to the ocean (Martin \& Meybec, 1979; Tréguer and De La Rocha, 2013). 
For example, in the Amazonian forest, the silica flux brought to the soil by litterfall (as phytoliths) is four times more important than the silica flux exported by the river (Lucas et al., 1993). Similarly, at Reunion Island, Meunier et al. (2001) found that the silica annually recycled by litter was similar to the chemical weathering flux estimated by Louvat \& Allègre (1997). The high solubilities of phytoliths and other amorphous silica particles in soils make them potentially significant contributors to the solute silica budget within the soil (Alexandre et al., 1997; Fraysse et al., 2010; Cornelis and Delvaux, 2016) and possibly to rivers. The biological control of silica fluxes in river systems can be observed in some streams, such as in Hawaii, using the Ge/Si ratio (Derry et al., 2005); more recently, this was observed in the experimental watershed of Mule Hole (Southern India) using combined solute mass balance at the soil-plant scale and hydrological modelling (Riotte et al., 2014a).

Because silicon isotopes are fractionated during interactions between water, soil and plants, the isotopic signature $\left(\delta^{30} \mathrm{Si}\right.$ values) of these compartments has the potential to trace the origin of the silica fluxes exported from watersheds (e.g., Cardinal et al., 2010; Opfergelt and Delmelle, 2012; Hughes et al., 2013). The fractionation of silicon isotopes is significant in natural environments, particularly in the various compartments of the Critical Zone (i.e., Earth's surface zone, encompassing groundwater, soils, rivers and vegetation), with values up to $12 \%$ (see reviews in Opfergelt and Delmelle, 2012, Frings et al., 2016). The lightest Si isotopic compositions are found in the silicification zones of aquifers $\left(\delta^{30} \mathrm{Si}=-5.7 \%\right.$, BasileDoelsch et al., 2005), while the heaviest ones are observed in some vegetation components $\left(\delta^{30} \mathrm{Si}=+6.1 \%\right.$, Ding et al., 2005).

The use of $\delta^{30} \mathrm{Si}$ as a tracer of biogeochemical cycling in watersheds is complex. Both the formation of clay minerals during weathering and biological uptake result in the preferential incorporation of the light ${ }^{28} \mathrm{Si}$ isotope relative to the heavier ${ }^{29} \mathrm{Si}$ and ${ }^{30} \mathrm{Si}$ isotopes (see review in Poitrasson, 2017). The silicon isotope fractionation factors (expressed as $\Delta^{30} \mathrm{Si}$ rather than using the ${ }^{30} \varepsilon$ Si notation, see Poitrasson, 2017) between parent and authigenic minerals are therefore negative. They range from $-1 \%$ for the adsorption of $\mathrm{Si}$ onto ferrihydrite (Delstanche et al., 2009) to -1.5 and $-2 \%$ for the incorporation of Si into allophane and kaolinite (Ziegler et al., 2005; Georg et al., 2007). Some of the mechanisms controlling this fractionation factor during water-mineral interactions were recently identified through laboratory experiments. During the abiotic precipitation of amorphous silica (further referred to as ASi), Geilert et al. (2014) observed that the isotopic fractionation between precipitated and dissolved Si decreased with increasing temperature from $-2.1 \%$ at $10^{\circ} \mathrm{C}$ to almost $0 \%$ 
beyond $50^{\circ} \mathrm{C}$. Geilert et al. (2014) suggested that the effect of temperature on isotopic fractionation is "system-dependent", i.e., indirect and primarily linked to the saturation level of the solution, changes in reactive surface area and the flow regime. Although the silica saturation levels of soil pore water can be easily estimated in natural systems, assessing soil reactive surface areas and flow regimes remains challenging.

The use of $\delta^{30} \mathrm{Si}$ as a tracer for studying the silica cycle in vegetation is also not straightforward for two reasons. First, the range of $\delta^{30} \mathrm{Si}$ values in worldwide plants, as well as in the phytoliths they produce, exceeds $8 \%$ (Frings et al., 2016), which means that cycling through plants does not induce a specific isotopic signature. However, if the $\delta^{30} \mathrm{Si}$ signatures of all plants in a given ecosystem are "system-dependent", they should vary within a narrow range, as observed in a boreal forest (Engström et al. 2008). In this case, $\delta^{30} \mathrm{Si}$ signatures could be used to trace the contribution of vegetation to the silica cycle in ecosystems and river systems, providing that the "vegetation signature" is distinct from the signature induced by silicate weathering (i.e., the dissolution of primary minerals and the precipitation of clay minerals) or adsorption/desorption processes. Second, significant isotopic fractionation also occurs within plant compartments, with large inter-specific variations. For instance, Ding et al. (2005) reported a large increase of $\delta^{30} \mathrm{Si}$ within rice plants, from $-1 \%$ in roots to $+6 \%$ in grain, while Opfergelt et al. (2006) observed a limited increase of $0.26 \%$ from pseudostems to leaves in banana plants. According to these authors, the magnitude of isotopic fractionation within a plant is related to the intensity of evapotranspiration, which, to some extent, is also a "system-dependent" parameter.

In the Mule Hole watershed (which has been monitored as a Critical Zone Observatory (CZO) since 2003), South India, the prominent role of vegetation in the water cycle and the biogeochemical cycle has previously been demonstrated (Ruiz et al., 2010; Riotte et al., 2014 a, b). For instance, evapotranspiration accounts for at least $80 \%$ of the water balance and controls the decennial fluctuation of the water stock in the vadose zone, as well as runoff and groundwater discharge (Maréchal et al., 2009; Ruiz et al., 2010). In addition, the silica flux annually recycled through the litter compartment represents 10 to 15 times the dissolved silica flux exported by the stream and dominates the solute mass balance at the soil-plant scale. However, assessing the respective fluxes of plant uptake and silicate weathering within the soil layer requires more constraints than solute mass balance at the soil-plant scale.

By taking advantage of the decennial hydro-geochemical monitoring of the Mule Hole watershed and subsequent recent elemental budgeting (Riotte et al., 2014a, b), the objective of 
the present study is to describe the processes affecting silica during water-soil-plant interactions and the impact of these processes on Si mass balance using the silicon isotopic signatures $\left(\delta^{30} \mathrm{Si}\right)$ of the dissolved and solid water-soil-plant compartments. This study also represents an opportunity to assess the potential and limitations of $\delta^{30} \mathrm{Si}$ as a tracer of silica sources at both the soil-plant and watershed scales. First, the morphotypes and isotopic compositions of amorphous silica particles (ASi) (i.e., phytoliths) are characterized and compared with those of fresh litter, soils and stream suspended loads. Second, the $\delta^{30} \mathrm{Si}$ signature of ASi dissolution is assessed from environmental samples (i.e., overland flow water, which gathers water from canopy and forest floor interactions) and batch leaching experiments. Third, solute isotopic budgets are carried out at the soil-plant and watershed scales to assess the identified processes and sources controlling the silica cycle in this forested watershed, including the hourly and seasonal $\delta^{30} \mathrm{Si}$ fluctuations in the stream.

\section{Environmental settings}

The experimental watershed of Mule Hole, which has an area of $4.1 \mathrm{~km}^{2}$, is located at $11^{\circ} 430 \mathrm{~N}-76^{\circ} 260 \mathrm{E}$ within the Cauvery Basin, on the Deccan Plateau, in the subhumid zone of the climatic gradient induced by the Western Ghats. The bedrock is composed of $85 \%$ Precambrian peninsular gneiss (metasediments, Shadakshara Swamy et al., 1995) containing quartz, oligoclase, sericite, biotite and chlorite as major minerals. In Mule Hole, the average regolith consists of 15-m-thick immature saprolite and 2-m-thick soils (Braun et al., 2009). The soil comprises a ferralsol-vertisol system (Barbiero et al. 2007, 2010). The alternation of subhumid and semi-arid conditions at Mule Hole during at least the Quaternary (Violette et al., 2010a) limited the intensity of chemical weathering and allowed the preservation of few primary minerals, such as Na-plagioclase and sericite, in soils. The secondary mineral assemblages in the ferralsol profile comprise kaolinite and Fe-oxyhydroxides, and those in the vertisol areas comprise a mix of kaolinite, smectite, Fe-oxyhydroxides and relics of pedogenic carbonates (Barbiero et al., 2010, Violette et al., 2010a). Four associations of soils and bedrocks were found and defined (Fig. 1): (A) ferralsol on gneiss, which is the most abundant; (B) vertisol on amphibolite; (C) shallow ferralsol on gneiss; and (D) vertisol on gneiss in valley bottoms.

The annual rainfall at Mule Hole has varied from 800 to $1500 \mathrm{~mm} / \mathrm{yr}$ over the last 35 years, with an average value of $1100 \mathrm{~mm} / \mathrm{yr}$. The hydrological modelling of the watershed (Violette et al., 2010b) and End-Member Mixing Analysis (Riotte et al., 2014a; Audry et al., 2014) 
indicate that the stream flow is mostly composed of overland flow (>90\%), i.e., rainwater having interacted with the canopy and then at the ground surface with decaying litter. Soil pore water contributes the last $10 \%$ during flood recessions, when soils are saturated at the end of monsoon season.

The vegetation cover is a dry deciduous forest (Barbiero et al., 2007), with the Anogeissus Tectona - Terminalia (ATT) facies (70\% of the watershed area) developed principally on ferralsols and less frequently on vertisols. Shallow ferralsols are also covered by Shorea trees (Shorea Roxb. ex C.F.Gaertn), and vertisols are covered by Ceriscoides turgida (Hook.f.) Tirveng. Litter fall occurs within a short period of time after monsoon season, typically from December to February.

The isotopic budgets of the present study rely on the solute mass balances recently performed at two spatial scales in order to understand the biogeochemical processes and their impact on the solute fluxes exported from the watershed: (1) those at the soil-plant profile scale, assessed using the hydrological modelling output for water fluxes and the chemical compositions of rainfall, throughfall, overland flow and soil pore water samples (Riotte et al. 2014a; Braun et al., 2017); and (2) those at the watershed scale, assessed using the hydrological modelling output for water fluxes and the chemical compositions of the stream (Violette et al., 2010b, Maréchal et al. 2011).

\section{Materials and methods}

\subsection{Water, soil, bedrock and vegetation sampling}

The water samples analysed in this study for their $\delta^{30} \mathrm{Si}$ values, namely, stream water, overland flow, soil porewater and groundwater, were analysed during the broader, long-term monitoring of the Mule Hole watershed, which is an environmental observatory (BVET, see https://mtropics.obs-mip.fr/experimental-tropical-watersheds-2/) (Fig. 1). The sampling and storage protocols are described in Riotte et al. (2014a). Stream water was sampled on an hourly basis, and groundwater was sampled on a monthly basis. The stream samples selected for $\delta^{30} \mathrm{Si}$ measurements $(\mathrm{n}=11)$ were chosen in order to cover both hourly and seasonal fluctuations in the stream composition in 2004 and 2005 (see Electronic Annex EA-1). In March 2004, the litter was burnt by a forest fire during the dry season. The two first short storms that occurred a few days later (i.e., in April and May, each with a 3-hour duration) exhibited particularly high silica concentrations (Audry et al., 2014) and were thus selected to 
assess the signal of litter ash leaching. One major storm (with a 48-hour duration) that occurred in the middle of the 2004 monsoon season, and is thus more representative of the hydrological functioning of the watershed, was also analysed for its $\delta^{30} \mathrm{Si}$ composition. In 2005, stream storm samples were collected during the first short storm in the summer season (April) and at the end of the monsoon season, when the soil layer was saturated (November). Overland flow samples $(n=7)$ were collected during the 2009 monsoon season on the ferralsol and vertisol/ferralsol transition (see below and Riotte et al., 2014a for sampling setup); each sample integrated overland flow events for two to three weeks. Deep groundwater samples were collected at 4 locations in 2005: 2 were collected close to a transect crossing the outlet, and 2 others were collected along the crest line (P5 in gneiss, P6 in amphibolite). Soil pore water samples were collected in vertisol seepage within the streambed in $2004(n=5)$ and in ferralsol/vertisol transition seepage in 2009 and $2010(n=4)$. All water samples were filtrated in the laboratory soon after collection (Sartorius ${ }^{\circledR}$ cellulose acetate, $0.22-\mu \mathrm{m}$ membrane).

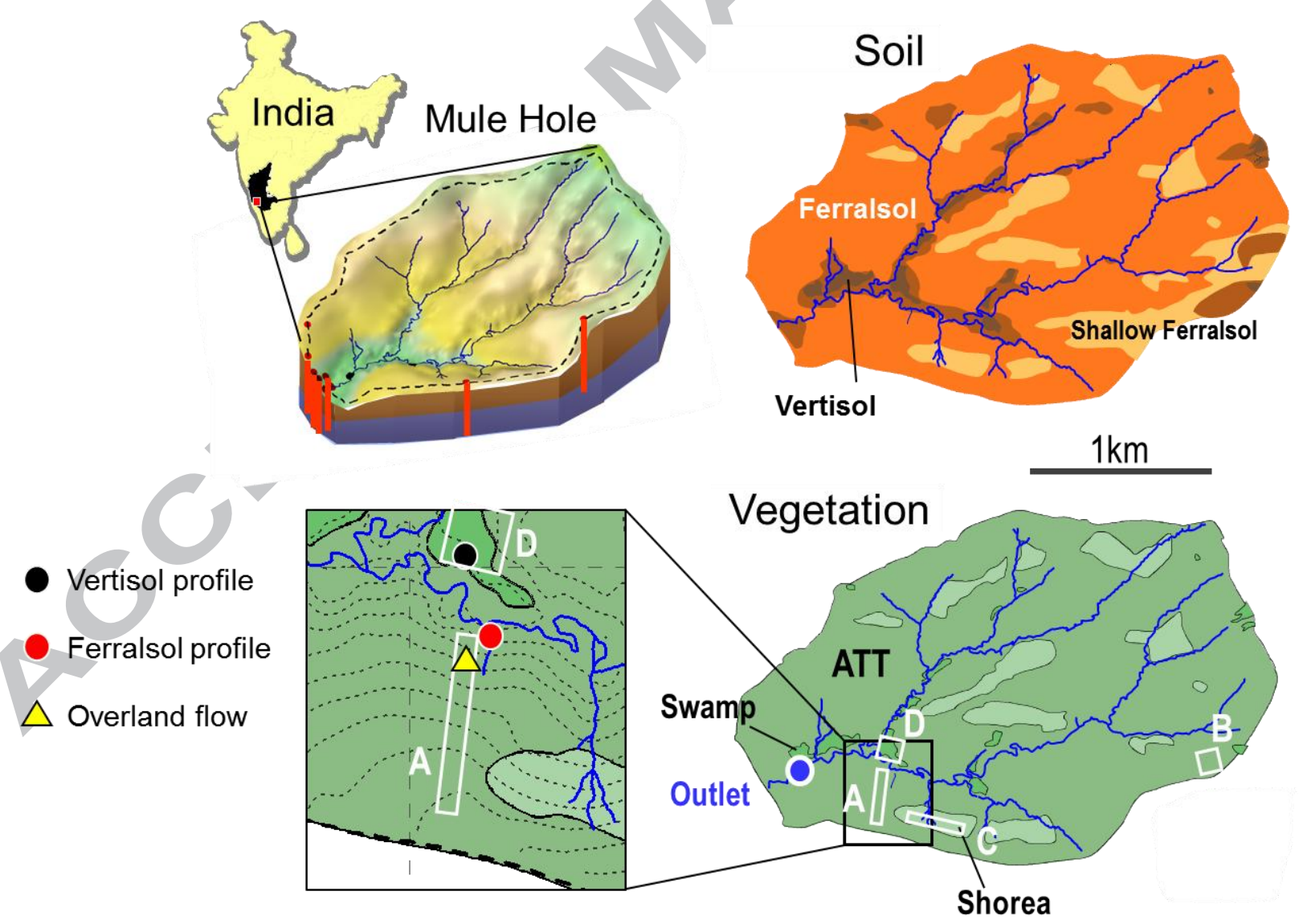

Fig. 1: The Mule Hole watershed with soil and vegetation map, showing the sampling locations of composite soils (plots $A, B, C, D$; see text for description), soil profiles, overland flow and ground water (modified from Riotte et al., 2014a). ATT (medium green): Anogeissus - Tectona - Terminalia facies. Dark green: swamp facies; light green: Shorea facies. 
Soil samples were selected from two well-documented soil profiles, one in ferralsol ( 5 depths) and one in vertisol (4 depths). Their mineralogy, granulometry, cation exchange capacity and major and trace element contents are summarized in Electronic Annex EA-2 and given in detail in Violette et al. (2010a and 2010b). Composite surface soils are composed of 36 to 42 samples collected between depths of 0 and $10 \mathrm{~cm}$ within a one-hectare plot of each soil and bedrock association (Fig. 1): (A) ferralsol on gneiss, (B) vertisol on amphibolite, (C) shallow ferralsol on gneiss and (D) vertisol on gneiss. Approximately $100 \mathrm{~g}$ of each soil sample was sieved with water to sizes of $2 \mathrm{~mm}$ and $50 \mu \mathrm{m}$. The $<2 \mathrm{~mm}$ fraction was considered to represent the bulk soil. The $<2 \mu \mathrm{m}$ fraction was recovered from the $<50 \mu \mathrm{m}$ fraction after the decantation of the coarse particles according to Stokes' law. Bulk soils and the $<2 \mu \mathrm{m}$ fraction were further dried and powdered with an agate mortar. A fresh bedrock sample was collected at a depth of $50 \mathrm{~m}$ as drilling cuttings when the "P5" piezometer was drilled. Its chemical composition corresponds to the average gneiss composition estimated by Braun et al. (2009).

Leaf and herbaceous litters were collected in large bags during the dry seasons of 2009 and 2010 from the dominant soil/vegetation configuration in the watershed, i.e., ATT vegetation developed on ferralsol. Litter samples consisted of A. latifolia, T. grandis and T. crenulata leaves and $T$. triandra grass. The litter of $T$. grandis was picked up as dry leaves on the ground in January and March 2009 and 2010. The leaves of A. latifolia and T. crenulata, which are more difficult to identify once they have fallen, were harvested on trees during their senescence in January. T. triandra was also cut in January, priori to senescence. All litter samples were dried at $70^{\circ} \mathrm{C}$ and powdered in an agate mortar (using the protocol detailed in Riotte et al., 2014a). The silica content of A. latifolia leaves was very low, i.e., $0.04 \%$ Si dry weight (DW), which is close to the detection limit (Riotte et al., 2014a). Because this species was unlikely to contribute to silica cycling, $\delta^{30} \mathrm{Si}$ analyses were restricted to the three species containing measurable silica, i.e., T. triandra grass (1.88 \% Si DW), T. grandis $(1.97 \% \mathrm{Si}$ DW) and $T$. crenulata (0.4\% Si DW) leaves.

\subsection{Assessment of $\delta^{30}$ Si during ASi dissolution}

Assessing the $\delta^{30} \mathrm{Si}$ value of ASi dissolution is of primary importance for tracing the origin of silica in rivers and assessing the consistency between elemental and isotopic mass balances. Two approaches were used in this study, namely, one onsite approach and one experimental approach. 
The onsite approach relied on the dominant contribution of ASi dissolution to overland flow (Riotte et al., 2014a). Overland flow ( $n=7)$ samples were collected close to the streambed at the ground surface using a PVC pipe connected to a buried can during the 2009 and 2010 monsoon seasons. Each collector drained an area of approximately $100 \mathrm{~m}^{2}$ and integrated several weeks of intermittent flow. The chemical compositions of overland flow and soil pore water are given in Riotte et al. (2014a). One advantage of using overland flow is that each sample integrates a significant area $\left(\sim 100 \mathrm{~m}^{2}\right)$ and several ephemeral flow events. The limit of this approach is the long interaction, i.e., up to two weeks, between the finest particles (likely phytoliths) and the solution collected in the sampling can, which can prevent the detection of possible kinetic isotopic fractionation occurring during $\mathrm{ASi}$ dissolution. The possible contribution of dust was extensively discussed in Riotte et al. (2014). It was considered to be negligible ( $3 \%$ of the Si concentration in overland flow) because the throughfall contained very low Si contents. Also, the ASi origin of Si in overland flow is supported by the good relationship between its $\mathrm{Si} / \mathrm{Na}, \mathrm{DOC} / \mathrm{Na}, \mathrm{Ca} / \mathrm{Na}$ ratios, which all increase during the monsoon season as litter decays, as well as by the oversaturation of overland flow solutions with respect to clays (Riotte et al., 2014a).

The experimental approach, as described in detail in Audry et al. (2014), was performed on litter ash from the ATT vegetation species. It consisted of 2-step batch experiments (with a solid/solution ratio of $2 \mathrm{~g} \mathrm{~L}^{-1}$, i.e., close to field conditions) and was designed to assess the impact of forest fires on the Mule Hole stream composition. In the first step, a mixture of ash/deionized water was filtered after 5 minutes of interaction to quantify and remove the easily dissolving salts present in the ash that would have dissolved during the first rainfall event. In the second step, the deionized water was renewed with the same solid/solution ratio. The leaching progress was monitored by periodically sampling the suspension without stopping the stirring in order to maintain a constant solid/solution ratio during the full duration of the experiment. The suspension aliquots were filtered, and the filtrates were analysed for their major dissolved species, including silica. The $\delta^{30} \mathrm{Si}$ signatures were determined for the filtrates retrieved from the first step of the experiment and the filtrates retrieved after 100 hours of interaction for the three species containing measurable silica, i.e., T. triandra grass, T. grandis and T. crenulata leaves. After 100 hours of interaction, the Si concentration in the leachate had reached its maximum value, i.e., $2.83 \mathrm{mmol} \mathrm{L}^{-1}$ for $T$. grandis and $3.18 \mathrm{mmol} \mathrm{L}^{-1}$ for T. triandra (see Electronic Annex EA-3, data from Audry et al., 2014) beyond saturation with amorphous silica $\left(\sim 210^{3} \mu \mathrm{mol} \mathrm{L}{ }^{-1}, \log \mathrm{K}=-2.71\right.$; Parkhurst and Appelo, 1999). The amount of silica released by T. crenulata from the first step was too 
small to allow the determination of $\delta^{30} \mathrm{Si}$; thus, for this species, $\delta^{30} \mathrm{Si}$ could only be measured in the filtrate after 100 hours.

\subsection{Amorphous Si and Dissolved Si measurements}

The ASi pool was separated from the soil (5 $\mathrm{g}$ aliquot) and suspended load (0.6 to $3 \mathrm{~g}$, based on sample availability) matrices using heavy liquid flotation. This method allows the quantification and identification of phytolith morphotypes and diatom frustules by optical microscopy (Kelly, 1990). The procedure includes overnight carbonate removal with $37 \%$ $\mathrm{HCl}$, the oxidation of organic matter $(\mathrm{OM})$ with $33 \% \mathrm{H}_{2} \mathrm{O}_{2}$ at $50-70{ }^{\circ} \mathrm{C}$, and clay removal by decantation with sodium hexametaphosphate to ease deflocculation. To remove heavy minerals, we used $\mathrm{ZnBr}_{2}$ heavy liquid $\left(\mathrm{d}=2.3 \mathrm{~g} \mathrm{~cm}^{-3}\right)$. After observing under the microscope that ASi is mainly composed of phytoliths, we calculated the concentration of Si from ASi/phytoliths assuming a mean water content in opal of $10 \%$ (Bartoli \& Wilding, 1980), which is equivalent to 0.37 moles of $\mathrm{H}_{2} \mathrm{O}$ for 2 moles of $\mathrm{SiO}_{2}(\mathrm{ASi}=0.42 \times$ mass of phytolith). This is referred herein as $\mathrm{ASi}_{\mathrm{zb}}$. This extraction protocol may lead to the underestimation of ASi due to phytolith loss during extraction or to the overestimation of ASi when the final fraction is not pure and contains organic compounds or mineralogical residues (Meunier et al., 2014). Because mineralogical residues (typically clays) could impact the estimation of ASi and alter the $\delta^{30} \mathrm{Si}$ signatures of phytoliths, we used a purity index based on the chemical composition of the $\mathrm{ASi}_{\mathrm{zb}}$ fraction. The chemical composition was determined after the alkaline digestion of ASi with $\mathrm{NaOH}$ (see section 3.4) with an ICP-OES Horiba Ultima Expert at GET. The purity of the $\mathrm{ASi}_{\mathrm{zb}}$ fractions was determined using the relation

$$
\mathrm{ASi}_{\mathrm{zb}} \text { purity }=(\mathrm{Si}-\Sigma(\mathrm{Al}, \mathrm{Fe}, \mathrm{Ca}, \mathrm{Mg}, \mathrm{Mn}, \mathrm{K})) / \mathrm{Si}
$$

where concentrations are expressed in $\mathrm{mol} \mathrm{g}^{-1}$. Using this index (dimensionless), pure amorphous silica would exhibit an $\mathrm{ASi}_{\mathrm{zb}}$ purity of 1 and clay would exhibit a value close to 0 . For each sample, the mass of ASi/phytoliths that was extracted was expressed as a percentage of the sample dry weight (\% DW).

The $\mathrm{ASi}_{\mathrm{zb}}$ contents were measured along the two vertisol and ferralsol reference profiles, on three suspended loads of streams and overland flow and on four composite 0-20 cm soils corresponding to the four vegetation-soil-bedrock occurrences in the watershed: (A) ferralsol developed on gneiss with ATT vegetation facies (dominant configuration), (B) vertisol developed on amphibolite with ATT vegetation facies, (C) shallow and sandy ferralsol 
developed on gneiss and covered with Shorea and (D) vertisol developed on gneiss and covered with Ceriscoides. The $\mathrm{ASi}_{\mathrm{zb}}$ data from the 5 vertisols and one ferralsol reported in Table 2 are from Meunier et al. (2014).

The dissolved Si concentrations (DSi) of stream, overland flow, soil pore water and groundwater samples were determined with a Hach® spectrophotometer at the Indo-French Cell for Water Sciences (IISc, Bangalore) using the molybdate blue method, with a precision of better than $10 \%$. The analytical quality was assessed using Perade-09 certified reference material.

Plant samples were first digested using a mixture of concentrated $\mathrm{H}_{2} \mathrm{O}_{2}$ and $\mathrm{HNO}_{3}$. The residual silica fraction, which was mainly composed of phytoliths, was dissolved separately using concentrated $\mathrm{NaOH}$. Samples were then homogenized, and their silica concentrations were determined with an ICP-OES Horiba Ultima Expert at the GET lab (Toulouse, France). Soil samples from vertisol and ferralsol profiles were analysed for their major (including Si) and trace elements by ICP-OES at the SARM (Nancy, France) after digestion by borate fusion. The Si concentrations of ash samples were determined by ICP-OES after alkaline $\mathrm{NaOH}$ digestion at GET. The overall precision obtained for the concentration measurements in solids was 5 to $10 \%$.

\section{4 $\delta^{30}$ Si measurements}

Solid samples (soils, litter and $\mathrm{ASi}_{\mathrm{zb}}$ ) dedicated to $\delta^{30} \mathrm{Si}$ measurements were digested and purified following the procedure described in Zambardi and Poitrasson (2011), which was itself modified from Georg et al. (2006). Soil and bedrock samples were powdered in an agate mortar, whereas litter samples were calcined at $900^{\circ} \mathrm{C}$ for 3 hours. Approximately $5 \mathrm{mg}$ of powdered sample was melted with an $\sim 200 \mathrm{mg} \mathrm{NaOH}$ pellet in a silver crucible and then dissolved in water and diluted $\mathrm{HCl}$.

The silicon fraction was separated from cations by column chromatography using Bio-Rad AG50W-X12 cationic resin. Si recovery was very close to $100 \%$. Procedural blanks were lower than $50 \mathrm{ng} \mathrm{Si}$, i.e., negligible compared to the amount of $\mathrm{Si}$ in each sample. Prior to isotopic measurements, the purified $\mathrm{Si}$ fraction was diluted to 2 or $3 \mathrm{mg} \mathrm{L}^{-1}$ based on the initial amount of $\mathrm{Si}$; the $\mathrm{HCl}$ concentration was adjusted to $0.05 \mathrm{~mol} \mathrm{~L}^{-1}$; and $1 \mathrm{mg} \mathrm{L}^{-1}$ of $\mathrm{Mg}$ was added as an internal standard for correcting online mass bias variations during the analysis. Isotopic compositions were measured using a Neptune (Thermo®) multi-collector ICP-MS in dynamic multicollection mode using medium- or high-resolution slits following 
the methodology of Zambardi and Poitrasson (2011). The reference material NBS 28, which was also spiked with $1 \mathrm{mg} \mathrm{L}^{-1}$ of $\mathrm{Mg}$, was measured between each sample (sample-standard bracketing). Most sample measurements were replicated 3 to 6 times. Isotopic data were normalized to NBS 28 and expressed as:

$\delta^{30}$ Si $(\% 0)=\left(\frac{\left(\frac{{ }^{30} \text { Si }}{{ }^{28} \text { Si }}\right)_{\text {sample }}}{\left(\frac{{ }^{30} S i}{{ }^{28} S i}\right)_{\text {NBS } 28}}-1\right) .1000$

The uncertainty associated with the $\delta^{30} \mathrm{Si}$ data (2SE) corresponds to two standard errors obtained from the 3 to 6 replicates. The reproducibility was assessed by regular measurements of the reference material BHVO-2 (basaltic rock). The average $\delta^{30} \mathrm{Si}$ value obtained here for BHVO, i.e., $-0.27 \pm 0.06 \%$ ( $2 \mathrm{SD}, \mathrm{n}=24)$, matches those obtained by Abraham et al. (2008) ($0.29 \pm 0.11 \%$ ), Zambardi and Poitrasson (2011) (-0.27 $\pm 0.08 \%$ ), and Savage et al. (2012) ($0.30 \pm 0.09 \%$ o). The standard deviation of the BHVO-2 measurements $( \pm 0.06 \%$ o $)$ is considered here to represent the best achievable uncertainty of our $\delta^{30} \mathrm{Si}$ data.

\subsection{Phytolith morphotypes and pollen analysis}

Phytoliths extracted from the soil and suspended load samples by heavy liquid flotation were analysed under the microscope to evaluate the relative contributions of various plant types to the pool of ASi in the Mule Hole soils. Slides were mounted using Canada balsam. Phytolith morphotypes were described and counted at x400 and x1000 magnifications. They were classified based on their 3D shapes and surface textures (Madella et al. 2005). They were then assigned their most likely botanical origin (grass, sedge, forest indicator, or non-diagnostic) according to e.g., Krishnan et al. (2000), Piperno (2006), Collura and Neumann (2016).

Pollen was extracted from eight soil samples -4 from each composite surface soil from the one-hectare plots and 4 from the vertisol profile (site D, Fig. 1) following standard protocols (Faegri et al., 1991 and Moore et al., 1991). Only seven of these samples could be analysed microscopically, as one contained too little pollen. Pollen taxa were counted under x400 and x1000 magnifications and identified using regional pollen atlases (Huang, 1972; Vasanthy, 1976; Nayar, 1990 and Tissot et al., 1994) as well as the Thanikaimoni pollen slide collection at the IFP as identification tools. The ecological attribution of the pollen taxa used here refers to Barboni and Bonnefille (2001), Barboni et al. (2003) and Anupama et al. (2014). 


\section{Results}

\section{1 $\delta^{30}$ Si values of bedrock, soils and suspended load}

The $\delta^{30} \mathrm{Si}$ value of the gneissic bedrock is $-0.34 \pm 0.08 \%$ (Table 1 ), which falls within the lowest part of the range defined for igneous rocks (Savage et al., 2012). The gneiss signature is consistent with the light signatures observed in metasediment-derived igneous bedrock (Savage et al., 2012, Poitrasson \& Zambardi, 2015). The isotopic signatures of the bulk ferralsol samples are very close to those of the bedrock composition. However, they slightly decrease with depth from $-0.26 \pm 0.08 \%$ at $0-20 \mathrm{~cm}$ to $-0.42 \pm 0.27 \%$ at $100-120 \mathrm{~cm}$. These signatures are heavier than most of the values reported for tropical soils (e.g., Opfergelt et al., 2009; 2012, Bern et al., 2010; Ziegler et al., 2005).

The clay-size fraction of ferralsol samples, which mostly comprises kaolinite, yielded a $\delta^{30} \mathrm{Si}$ value of $-1.30 \%(n=3)$, which is homogeneous in the soil profile. The fractionation factor between kaolinite and bedrock is thus close to $-1 \%$, which is less than the values that have been observed in other soils to date (Opfergelt and Delmelle, 2012 and references therein), which are closer to $-2 \%$.

The suspended load of the overland flow yielded a $\delta^{30}$ Si signature of $-0.90 \pm 0.14 \%$, which falls in between those of bulk soil and kaolinite, thus reflecting the mobilization of the fine grain size fractions from topsoil during rainy events.

\subsection{Contribution to amorphous Si in soils: ASi content, phytolith morphotypes, pollen analysis, $\delta^{30}$ Si of $A S i$}

\subsubsection{ASi content}

The amorphous silica $\left(\mathrm{ASi}_{\mathrm{zb}}\right)$ concentrations in the soil profiles range from 0.05 to $0.24 \%$ for ferralsol and from 0.06 to $0.86 \%$ for vertisol (Table 2). The degree of $\mathrm{ASi}_{\mathrm{zb}}$ purity was elevated $(>0.85)$ in surface soils and suspended load samples but decreased with $\mathrm{ASi}_{\mathrm{zb}}$ content and depth in soil profiles, down to 0.42 for the ferralsol sample collected at a depth of 200$220 \mathrm{~cm}$ (Table 2). The $\mathrm{ASi}_{\mathrm{zb}}$ concentrations in soils are comparable to those in other forest soils, both in humid tropics $(0.02 \%$ to $0.25 \%$, Congo, Alexandre et al., $1997 ; 0.3$ to $2 \%$, Cameroon, Cary et al., 2005) and temperate climates (0.3-1.4 \%, France, Cornelis et al., 2010). Their concentrations decreased with depth, as it is commonly the case in pristine tropical forests (Alexandre et al., 1997; Alexandre et al., 2011; Blecker et al., 2006; Saccone 
et al., 2007; Saccone et al., 2008). This distribution reflects a balance between litterfall input and the dissolution/preservation of phytoliths in the soil profile. The ASi stocks in ferralsol and vertisol, assessed by extrapolating the measured values to the 2-m-thick profiles, should then range from $4 \mathrm{~kg} \mathrm{~m}^{-2} \mathrm{Si}$ to $8 \mathrm{~kg} \mathrm{~m}^{-2} \mathrm{Si}$, respectively. These values are comparable to those observed in other mature tropical forests in Amazonia (Lucas, 2001) and the Congo (Alexandre et al. 1997) and are higher than those observed in savannas (Alexandre et al., 2011). The $\mathrm{ASi}_{\mathrm{zb}}$ values of the four composite surface soils ranged from 0.4 to $0.65 \%$. This narrow range suggests a homogeneous phytolith content at the soil surface of Mule Hole. The corresponding stock for the $15-\mathrm{cm}$ topsoil layer would be $1 \mathrm{~kg} \mathrm{~m}^{-2} \mathrm{ASi}$, which is equivalent to approximately 150 years of litter production (Riotte et al., 2014a) and 1000 to 2000 years of litter production for the whole soil layer.

\subsubsection{Phytolith morphotypes}

Phytolith counts are given in Electronic Annex EA-4 and summarized in Fig. 2. Under the microscope, the ASi appears to mostly comprise phytoliths. Diatoms represent less than $4 \%$ of all samples, including the stream and overland flow samples. The non-diagnostic elongate and blocky phytoliths are the dominant morphotypes (Fig. 2, micrographs in Electronic Annex AE-5) in all samples but the surface soil sample located in the Shorea forest, which contains abundant forest indicator phytoliths (Fig. 2). Grass/sedge indicators are more dominant than forest ones, but the abundance of grass/sedge indicators decreases with soil depth. The proportion of pitted phytoliths in ferralsol and vertisol profiles increases with depth, revealing an "aging effect" on deep phytoliths (Fig. 2).

\subsubsection{Pollen analysis}

Pollen counts are given in Electronic Annex EA-6. The analysis of the vertisol profile shows that more taxa with an affinity for evergreen forests are represented in the bottom of the vertisol profile $(100-160 \mathrm{~cm})$ compared to the top, which is characterized by pollen taxa with an affinity to moist deciduous forests (Electronic Annex AE-7). Changes associated with more seasonality and/or less annual precipitation are likely responsible for these changes in the pollen taxa composition through the vertisol profile at Mule Hole. 


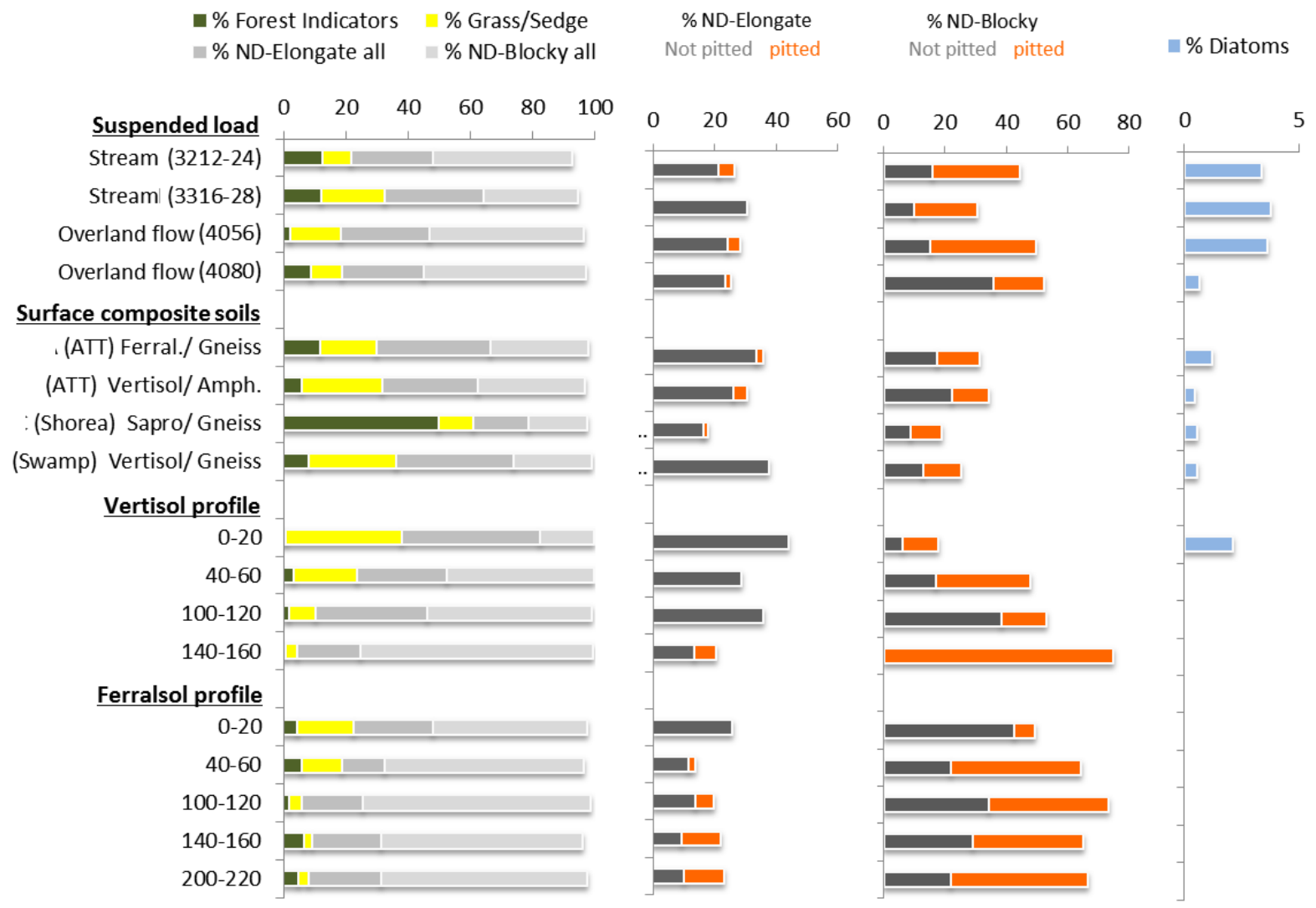

Fig. 2: Phytolith morphotypes and diatom contents in suspended load and soils of Mule Hole. ATT $=$ Anogeissus - Tectona - Terminalia facies. $N D=$ non-diagnostic.

\subsection{4 $\delta^{30}$ Si of $A S i$}

The raw $\delta^{30} \mathrm{Si}$ values in soil ASi range from $-0.36 \%$ (ferralsol at a depth of $100-120 \mathrm{~cm}$ ) to $1.56 \%$ (vertisol at a depth of $140-160 \mathrm{~cm}$ ), which is a particularly wide range. However, the comparison between raw $\delta^{30} \mathrm{Si}$ and $\mathrm{ASi}_{\mathrm{zb}}$ purity clearly shows that this variability is mostly due to impurities. The five ferralsol samples define a linear relationship $\left(R^{2}=0.997\right)$ between the fresh litter (leaves \& grass; $\mathrm{ASi}_{\mathrm{zb}}$ purity assumed to be 1 and an average measured $\delta^{30} \mathrm{Si}$ value of $1.25 \%$ ) and the clay end-member $\left(\mathrm{ASi}_{\mathrm{zb}}\right.$ purity $=0$ and $\delta^{30} \mathrm{Si}=-1.30 \%$; Fig. 3 ). 


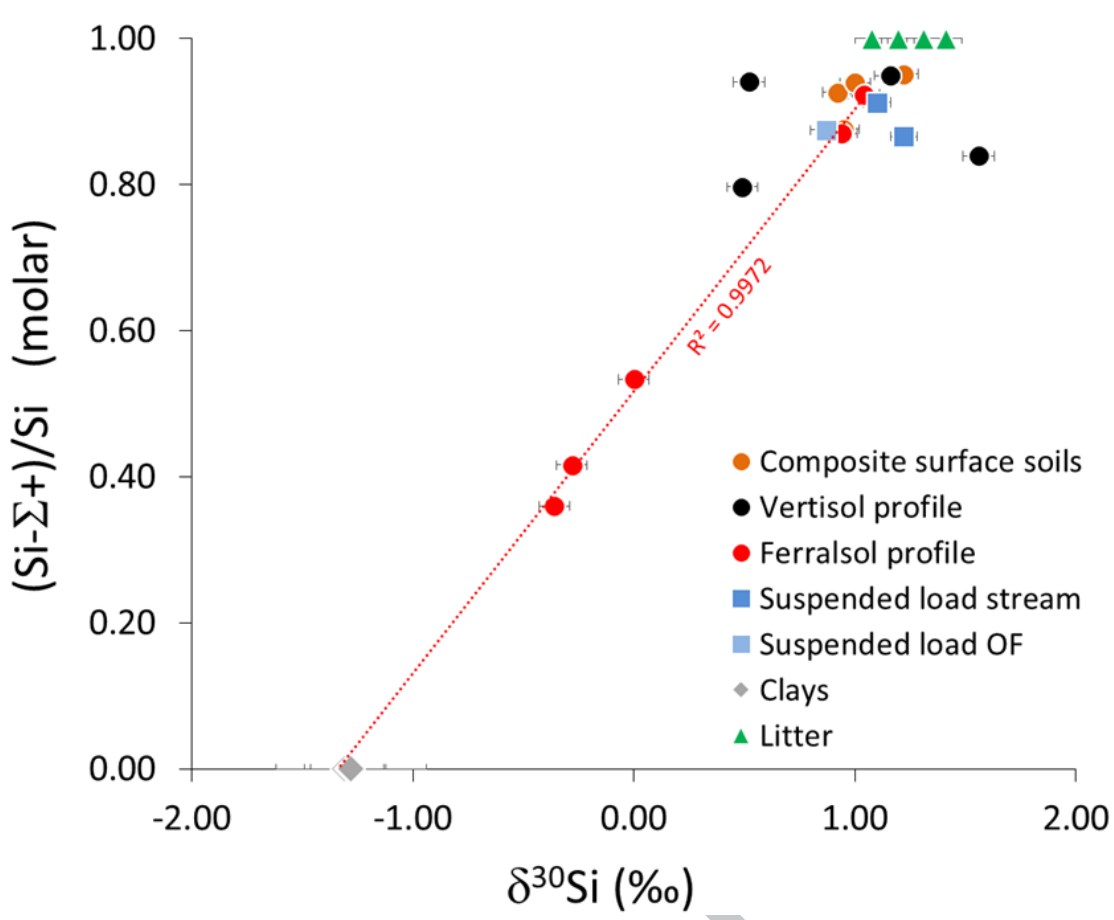

Fig. 3: Influence of purity on $\delta^{30}$ Si signatures in the ASi $i_{z b}$ fractions of surface soils, soil profiles and suspended load in Mule Hole. Purity index is defined as (Si$(A l+F e+C a+M g+M n, K)) / S i$. Purity index values of fresh litter and clays are theoretical. $O F=$ overland flow. This diagram shows that despite being apparently pure under microscope, the ASi fraction separated by dense liquor can still contain significant amounts of impurities that can impact the $\delta^{30} \mathrm{Si}$ signature of this fraction. Correcting for impurities allows us to recover the $\delta^{30} \mathrm{Si}$ value of the pure ASi fraction.

The $\mathrm{ASi}_{\mathrm{zb}}$ content of the stream suspended load (0.37-0.52\%, Table 2) reflects the values of the overland flow $(0.56 \%)$ and the average topsoil composition of the watershed, as more than $90 \%$ of the runoff originates from overland flow (Maréchal et al., 2009). The $\delta^{30} \mathrm{Si}$ signature of $\mathrm{ASi}_{\mathrm{zb}}$ in the suspended loads of overland flow and streams lies on the $\delta^{30} \mathrm{Si}$ vs $\mathrm{ASi}_{\mathrm{zb}}$ purity relationship defined by ferralsol, making the "pure" $\delta^{30} \mathrm{Si}$ value of the suspended load similar to the litter and surface soil signatures. In contrast to humid tropics, where the ASi of large rivers is dominated by diatoms (e.g., Hughes et al., 2011), our microscope observations indicate that in headwater streams such as Mule Hole or Mengong, Cameroon (Cary et al., 2005), ASi is almost exclusively composed of phytoliths. At Mule Hole, the ephemeral nature of the stream prevents diatom ingrowth. The similarities between the phytolith morphotypes of the stream, overland flow and ferralsol surface (Fig. 2) are consistent with the dominant contribution of overland flow on ferralsol to the ASi flux exported by the stream (Riotte et al., 2014a). 


\section{3 $\delta^{30}$ Si of natural solutions}

The $\delta^{30} \mathrm{Si}$ values of DSi in overland flow $(\mathrm{n}=7)$ ranged from $0.44 \pm 0.16 \%$ o to $2.22 \pm 0.69 \%$, with a cluster around $1.08 \pm 0.11 \%$ o $(n=5$; Table 3$)$. No shift in $\delta^{30} \mathrm{Si}$ was noticed during the rainy season, in contrast to the $\mathrm{Si} / \mathrm{Na}$ and $\mathrm{DOC} / \mathrm{Na}$ molar ratios, which increased as litter decayed (Riotte et al., 2014a). The $\delta^{30} \mathrm{Si}$ values of DSi in soil pore water was homogeneous whatever the soil type, $1.64 \pm 0.11 \%$ o $(n=9$; Table 3$)$.

Apart from the first two storms of 2004, during which litter-ash leaching released highly above-average Si fluxes (Audry et al., 2014) with specific $\delta^{30} \mathrm{Si}$ values, the $\delta^{30} \mathrm{Si}$ values of the stream water varied based on the water sources, with the lightest $\delta^{30} \mathrm{Si}$ values $(0.28$ to $0.74 \%$ o) occurring during flood peaks and the heaviest ones occurring during peak recession (1.04 to 1.61\%) (Table 3). Similar patterns were reported in tropical (Hughes et al., 2013) or temperate to boreal rivers (Georg et al., 2006; Engström et al. 2010; Pokrovsky et al., 2013). The range of $\delta^{30} \mathrm{Si}$ values in the Mule Hole stream of $1.3 \%$ is as wide as those observed in some large rivers, such as the Solimoes River from Amazonia (Hughes et al., 2013), which undergoes contrasted weathering regimes from the Andes to the Amazon plain, or Siberian rivers (1 to $1.5 \%$; Pokrovsky et al., 2013).

\section{4 $\delta^{30}$ Si values of ash leaching experiments}

Ash leaching batches display large isotopic fractionation during ASi dissolution, especially at short interaction times. Incipient ash leaching (5 minutes), which coincides with the dissolution of the most soluble and alkaline salts, yielded extremely light $\delta^{30} \mathrm{Si}$ values, i.e., $0.77 \pm 0.04 \%$ for $T$. triandra ash and down to $-1.41 \pm 0.02 \%$ for $T$. grandis ash. The solutions produced by long-term ash leaching (5 days) were isotopically heavier and fell within the range of the $\delta^{30} \mathrm{Si}$ values of phytoliths for $T$. triandra and T. crenulata, i.e., $1.45 \pm 0.07 \%$ and $1.17 \pm 0.06 \%$, respectively. The long-term ash leaching of $T$. grandis, yielded a $\delta^{30} \mathrm{Si}$ value of $2.29 \pm 0.02 \%$, which is significantly higher than the bulk signature and may have resulted from the small-scale heterogeneity of this sample. The $\delta^{30} \mathrm{Si}$ values of all three leaching experiments increased with the proportion of dissolved ASi, calculated as the amount of $\mathrm{Si}$ in solution divided by the initial amount of $\mathrm{Si}$ in the litter ash; with the notable exception of the long-term ash leaching of $T$. grandis, they all defined a broad trend matching that of another leaching experiment performed on Hawaiian phytoliths (Ziegler et al., 2005) (Fig 4). 


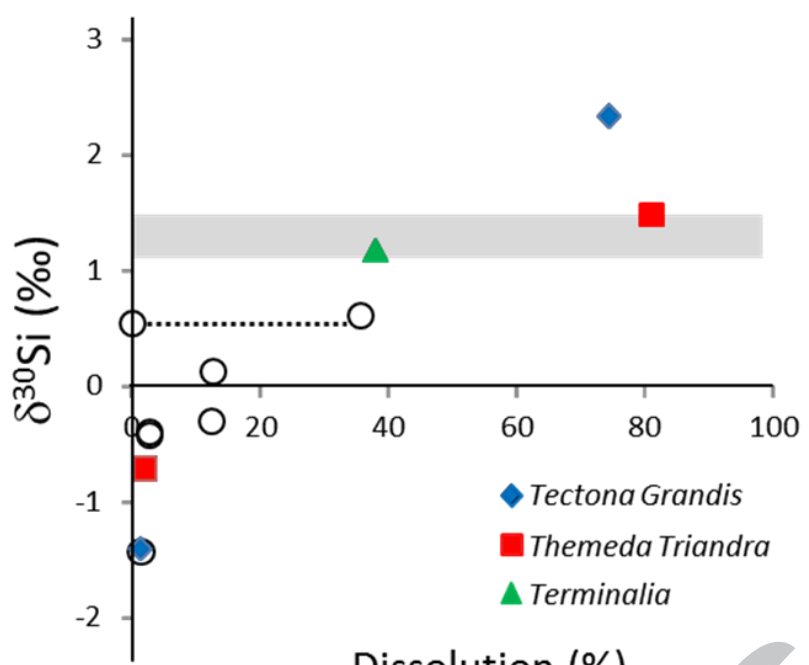

Dissolution (\%)

Fig. 4: Evolution of $\delta^{30} \mathrm{Si}$ in the dissolved phases of ash leaching experiments with the percentage of dissolved litter-Si (fraction of Si release divided by the total Si content in the bulk litter). Grey area: range of phytolith compositions found in this study. Open circles: phytolith dissolution experiments from Ziegler et al. (2005), with dotted line representing the isotopic composition of the phytolith.

\section{Discussion}

\subsection{Silicon pools in the soil and variability of $\delta^{30} \mathrm{Si}$-ASi in the watershed}

When compared to the weathering degree estimated from the Chemical Index of Alteration (Nesbitt and Young, 1982) or the Weathering Index of Parker (Parker, 1970), the Mule Hole soils (CIA 80 to 84, WIP 14 to 15) plot slightly away from the trend defined by worldwide soil data (Opfergelt \& Delmelle, 2012): for a given weathering index, the $\delta^{30} \mathrm{Si}$ values of the Mule Hole soils are heavier than those in most other locations. The narrow range of Si isotopic fractionation between the bedrock and soils of Mule Hole can be explained by the mineralogical composition of the soils and particularly by the partitioning of silicon between primary and secondary phases. Approximately 86 to $95 \%$ of soil silicon is still located in primary minerals (e.g., quartz, plagioclase), whereas only 4 to $13 \%$ is located in clay minerals, mostly kaolinite from ferralsols (Barbiero et al., 2007; Braun et al. 2009). Such clay mineral contents are low compared to those of 35 to $85 \%$ found, for instance, in Guadeloupe soils (Opfergelt et al., 2012). Quartz accounts for 70 to $79 \%$ of the total Si of the soil (Table 1) and therefore dominates the soil isotopic signature. The fact that quartz abundance is not considered in the calculation of weathering indices could explain why the Mule Hole data plot outside the trends of worldwide soil $\delta^{30} \mathrm{Si} v s$ weathering indexes (Opfergelt \& Delmelle, 2012), as well as the scattering of these trends. Our data confirm the conclusion of Opfergelt 
and Delmelle (2012) that the $\delta^{30} \mathrm{Si}$ values of bulk soils depend on the ratio of clay to primary minerals. The relatively high $\delta^{30} \mathrm{Si}$ value of the clay fraction could possibly be explained by a slight contribution of quartz to this fraction, which would slightly increase the $\delta^{30} \mathrm{Si}$ value, as was recently proposed by Ameijeiras-Mariño et al. (2017). Alternatively, some minerals of the bedrock could exhibit slightly heavier $\delta^{30} \mathrm{Si}$ values than the bulk rock, which could account for the limited apparent fractionation factor. However, the narrow range of $\delta^{30} \mathrm{Si}$ values observed for separate silicate minerals (Savage et al., 2014) or modelled between quartz and albite at $600{ }^{\circ} \mathrm{C}(<0.1 \%$, Méheut et al., 2014) makes this assumption unlikely.

The low purity index of $\mathrm{ASi}_{\mathrm{zb}}$ in deep ferralsol samples attests to the difficulty of recovering the soil ASi fraction, despite using an elaborate purification protocol (see section 3.2) and further microscope quality control. In contrast to the microscope control, which is qualitative, the chemical control, as assessed through the purity index, is sensitive and quantitative. It allows us to quantify contamination and correct the $\delta^{30} \mathrm{Si}$ value of ASi when necessary. In the case of deep ferralsol samples, the clay mineral contribution was significant and impacted the $\delta^{30} \mathrm{Si}$ of $\mathrm{ASi}_{\mathrm{zb}}$, which thus must be corrected. The alignment of the clay and fresh litter compositions of $5 \mathrm{ASi}_{\mathrm{zb}}$ ferralsol samples (Fig. 3) indicates that the $\delta^{30} \mathrm{Si}$ of $\mathrm{ASi}_{\mathrm{zb}}$ is constant along the ferralsol profile and corresponds to the average signature of fresh litter. It is remarkable that the $\mathrm{ASi}_{\mathrm{zb}} \delta^{30} \mathrm{Si}$ values of the four composite surface soils, the shallow vertisol sample and the suspended load of the overland flow and stream also lie close to the relationship defined by ferralsol samples, implying that the $\mathrm{ASi}_{\mathrm{zb}} \delta^{30} \mathrm{Si}$ can be corrected by extrapolation to an $\mathrm{ASi}_{\mathrm{zb}}$ purity of 1 . Then, the $\delta^{30} \mathrm{Si}_{\text {corr }}$ values of all these $\mathrm{ASi}_{\mathrm{zb}}$ samples (Table 2) fall within a narrow range, between 1.10 and $1.30 \%$, corresponding to the presentday litter phytolith composition.

In contrast to the ferralsol profile and composite surface soils, the ASi fractions of the vertisol profile exhibit scattered $\mathrm{ASi}_{\mathrm{zb}} \delta^{30} \mathrm{Si}$ compositions, i.e., from 0.52 to $1.56 \%$ (uncorrected from clay impurities), although the contribution of impurities does not exceed $20 \%$. If the clay signature in this soil profile is the same as that of the ferralsol, then the $\mathrm{ASi}_{\mathrm{zb}} \delta^{30} \mathrm{Si}_{\text {corr }}$ values of deeper vertisol samples should vary from 0.62 to $2.10 \%$. The presence of smectite in vertisols may induce a heavier $\delta^{30} \mathrm{Si}$ value of the clay pool, as was observed for another clay mineral, illite (-0.68\%o, Steinhofel et al., 2011). However, because of the purity level of the vertisol ASi fraction, the clay signature only marginally impacts the $\delta^{30} \mathrm{Si}_{\text {corr }}$ value; if the clays have a $\delta^{30} \mathrm{Si}$ value of $-0.5 \%$, the range of the $\delta^{30} \mathrm{Si}_{\text {corr }}$ values of deeper vertisol samples would be still 0.5 to $2.0 \%$. Rather, the scattered signatures could result from the impervious 
properties of vertisols (Kurtzman et al., 2016) that could host preserved phytoliths from past vegetation/climate conditions or have induced opal precipitation due to the intense evaporation of soil pore water. Pedogenic carbonates dated to the Last Glacial Maximum, when semi-arid conditions prevailed (Violette et al., 2010a), are present in the vertisols of Mule Hole. Given the low permeability of vertisols, phytoliths from this period could also have been preserved, which would also explain their higher abundance in vertisols compared to ferralsols. Indeed, the phytolith morphotypes at the vertisol surface (Fig. 2; Supplementary table 1), which are dominated by elongate shapes, differ from those of deeper horizons, where blocky shapes are dominant relative to elongate shapes. The antiquity of these phytoliths is indicated by an increase in the proportions of pitted phytoliths with depth, probably due to weathering over time, whereas the absence of cultivation pollen markers below a depth of 100 $\mathrm{cm}$ suggests that those soils were preserved from significant human impacts. A spike in certain ubiquitous pollen taxa in tandem with the spike in evergreen taxa below this depth suggests a mosaic landscape of patches or islands of wet/humid forests separated by openings, which is certainly different from the present landscape in terms of its species composition (Electronic Annex AE-7). Then, the large variability of $\mathrm{ASi}_{\mathrm{zb}} \delta^{30} \mathrm{Si}$ values in deeper vertisol horizons could come from phytoliths of a vegetation cover different than the present one. One cannot exclude that ageing effects also impacted $\mathrm{ASi}_{\mathrm{zb}} \delta^{30} \mathrm{Si}$. Alternatively, it is known that the seasonal swelling/cracking properties of vertisols favour pore water evaporation and then salinization (e.g., Baram et al., 2013). Deep soil pore water could then reach saturation with opal and allow opal precipitation at this depth. If this process is not completely reversible over a monsoon-dry season cycle, small amounts of opal could have accumulated over time in the soil and then contributed to the $\mathrm{ASi}_{\mathrm{zb}}$ fraction of deep vertisol samples, possibly also impacting the $\delta^{30} \mathrm{Si}$ signature of $\mathrm{ASi}_{\mathrm{zb}}$.

To summarize, apart from two depths in the vertisol in which phytoliths likely represent fossils of another vegetation cover, the $\delta^{30} \mathrm{Si}$ value of $\mathrm{ASi}$ remains remarkably constant throughout the watershed, which confirms that the $\delta^{30} \mathrm{Si}$ values of vegetation are "systemdependent" rather than "vegetation species-dependent" (Geilert et al., 2014). However, it remains unclear why two vertisol samples exhibit a wide range of $\mathrm{ASi} \delta^{30} \mathrm{Si}$ values, i.e.,, from 0.6 to $2.1 \%$. 


\subsection{Silicon isotopic solute mass balance at the soil-plant scale}

\subsubsection{Initial elemental Si mass balance}

The Si isotopic mass balance at the soil-plant scale (Fig. 5) relies on the initial elemental mass balance performed by Riotte et al. (2014a). At the ground surface, the solute $\mathrm{Si}$ flux infiltrating the soil layer (i.e., the soil input flux), assuming an overland flow composition, is $1850 \mathrm{~mol} \mathrm{ha}^{-1} \mathrm{yr}^{-1}$ of DSi, which is similar to that brought to the ground by litter fall, i.e., $2200 \pm 200 \mathrm{~mol} \mathrm{Si} \mathrm{ha}^{-1} \mathrm{yr}^{-1}$. The origin of the Si infiltrating the soil was assigned to ASi dissolution from litter, based on the good relationship between the Si/Na, DOC/Na, and $\mathrm{Ca} / \mathrm{Na}$ ratios that all increase during the monsoon season as litter decays. Since the $\mathrm{Na}$ concentration in overland flow was identical to that of rainfall and throughfall, the contribution of primary minerals, such as Na-plagioclase, to the overland flow solution was considered to be negligible, while its oversaturation with respect to clay minerals indicated that clays were not a potential source. Within the soil, the Si solute mass balance was performed using both $\mathrm{Si}$ and $\mathrm{Na}$ budgets (Fig. 5, left side, from Riotte et al., 2014a). With a DSi output of only $704 \pm 150 \mathrm{~mol} \mathrm{ha}^{-1} \mathrm{yr}^{-1}$, the input-output budget indicates an apparent loss of $1150 \mathrm{~mol} \mathrm{DSi} \mathrm{ha}^{-1} \mathrm{yr}^{-1}$ from the soil layer. However, the net soil output of $650 \mathrm{~mol} \mathrm{Na} \mathrm{ha}^{-}$ ${ }^{1} \mathrm{yr}^{-1}$, which could only originate from the weathering of Na-plagioclase, likely induced the release of an additional $1300 \mathrm{~mol} \mathrm{DSi} \mathrm{ha-1} \mathrm{yr}^{-1}$ if kaolinite is the weathering product, according to the following weathering reaction (Riotte et al., 2014a):

$2\left(\mathrm{Na}_{0.92} \mathrm{Ca}_{0.08}\right)\left(\mathrm{Al}_{1.07} \mathrm{Si}_{2.93}\right) \mathrm{O}_{8}+2 \mathrm{H}^{+}+9 \mathrm{H}_{2} \mathrm{O} \rightarrow 1.07 \mathrm{Si}_{2} \mathrm{Al}_{2} \mathrm{O}_{5}(\mathrm{OH})_{4}+1.84 \mathrm{Na}^{+}+0.16 \mathrm{Ca}^{2+}$ $+3.72 \mathrm{H}_{4} \mathrm{SiO}_{4}$

Then, according to this Na-Si solute budget, the DSi loss from the soil layer would be at least $2450 \mathrm{~mol} \mathrm{ha}^{-1} \mathrm{yr}^{-1}$; this value is similar to the annual litter flux (tree leaves and grass). The loss of Si from soil pore water was attributed to vegetation uptake.

\subsubsection{Si mass balance inferred from isotopes}

The Si mass balance inferred from isotopes consists of multiplying the elemental Si fluxes of section 5.2 .1 by their isotopic signature $\left(\delta^{30} \mathrm{Si}\right)$. When $\delta^{30} \mathrm{Si}$ values were obtained from several samples of a given compartment, the variability between these data was taken into account using two standard deviations between samples.

The elemental mass balance inferred from isotopes first provides the opportunity to test the assumption of the biogenic origin of Si in overland flow proposed by Riotte et al. (2014a). 
Accordingly, the three potential sources of $\mathrm{Si}$, namely, fresh litter $(1.25 \pm 0.14 \%$ ), primary minerals (-0.34\%o) and clay minerals (-1.30\%o), exhibit contrasting $\delta^{30} \mathrm{Si}$ values. The average $\delta^{30} \mathrm{Si}$ of overland flow DSi $(1.15 \pm 0.50 \%$ ) is much heavier than the signature of the clay-size fraction $(-1.30 \%$ ), thus ruling out any contribution of clay mineral dissolution to the silica content in overland flow. It is indeed slightly lower than the fresh litter average, $1.25 \pm 0.14 \%$, which is consistent with the fractionation factor $\Delta^{30} \mathrm{Si}_{\mathrm{ASi} \text {-DSi }}$ of $-0.26 \%$ estimated for ASi dissolution in the delta of Okavango (Frings et al., 2014a) and in the range observed during diatom dissolution, i.e., approximately $0 \%$ (Wetzel et al., 2014) to $-0.55 \%$ (Demarest et al. 2009). The similarity between the $\delta^{30} \mathrm{Si}$ values of overland flow and fresh litter leaves no doubt about the biogenic origin (phytolith dissolution) of DSi in overland flow. By extension, the biogenic origin of Si in solutions infiltrating the soil (Riotte et al., 2014a) is therefore confirmed.

The isotopic mass balance then allows us to evaluate whether the plant uptake of Si is limited to cycling through the litter or involves a larger flux with storage in the woody biomass. Tropical trees are known to accumulate silica in their woody stems; at least one of the most abundant tree species of Mule Hole, $T$. grandis, contains 0.27 to $0.66 \%$ of silica in its wood (Kjaer et al., 1999). If the $\mathrm{Si}$ stored in a plant were concentrated in the litter, $\delta^{30} \mathrm{Si}_{\text {uptake }}$ should be equal to $\delta^{30} \mathrm{Si}_{\text {litter, }}$, whereas if $\mathrm{Si}$ is partly stored in the woody biomass, $\delta^{30} \mathrm{Si}_{\text {uptake }}$ should differ from $\delta^{30} \mathrm{Si}_{\text {litter }}$ because Si isotopes fractionate within the plants (Opfergelt, 2006; Ding et al. 2005). The $\delta^{30} \mathrm{Si}_{\text {uptake }}$ can first be estimated from the solute isotopic budget within the soil layer, which requires an assessment of the $\delta^{30} \mathrm{Si}$ value of the silica released during plagioclase weathering. If plagioclase crystals break down into kaolinite with the release of dissolved $\mathrm{Na}$ and silica (a process referred to in Fig. 5 as plagioclase weathering and described by the above weathering reaction), the $\delta^{30} \mathrm{Si}$ value of the silica released can be estimated according to a mass balance equation (Bouchez et al., 2013):

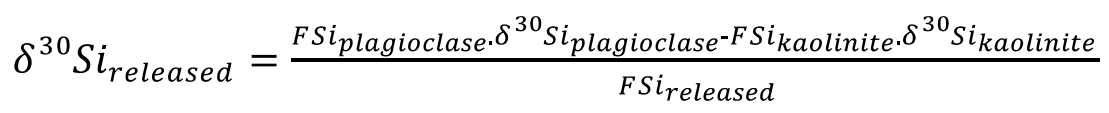

Using the reaction stoichiometry (FSi values) given in the weathering reaction (3) (from Riotte et al., 2014a) and the $\delta^{30} \mathrm{Si}_{\text {kaolinite }}$ values measured in ferralsol clays $(-1.30 \pm 0.03 \%$ o

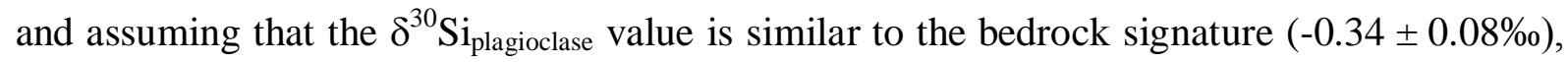
the estimated $\delta^{30} \mathrm{Si}_{\text {released }}$ value produced by Na-plagioclase weathering would be 
$+0.21 \pm 0.14 \%$. Adding the DSi flux infiltrated from the surface $\left(1850 \mathrm{~mol} \mathrm{ha}^{-1} \mathrm{yr}^{-1}\right.$ with $\delta^{30} \mathrm{Si}$ of $1.15 \pm 0.50 \%$ ) to the Si released by Na-plagioclase weathering indicates that the minimum DSi flux to the soil would have an average $\delta^{30} \mathrm{Si}$ value of $+0.76 \pm 0.35 \%$. Since the soil output of $842 \mathrm{~mol} \mathrm{DSi} \mathrm{ha}{ }^{-1} \mathrm{yr}^{-1}$ (Riotte et al., 2014a) has an average $\delta^{30} \mathrm{Si}$ value of $+1.64 \pm 0.11 \%$, the silica removed from soil pore water and assigned to plant uptake should exhibit a $\delta^{30} \mathrm{Si}$ value of $+0.52 \pm 0.30 \%$. This signature is $0.7 \%$ o lower than the average $\delta^{30} \mathrm{Si}_{\text {litter }}$ value, which means that plants likely take up more silica than expected from the elemental mass balance. Therefore, the latter must be re-evaluated and isotopically equilibrated.

\subsubsection{Equilibration of the Si isotopic mass balance}

In this section, we propose a three-step methodology for equilibrating the $\mathrm{Si}$ isotopic mass balance, which consists of (1) estimating the $\delta^{30} \mathrm{Si}$ value of the bulk Si taken up by plants, (2) estimating the corresponding flux of the bulk Si uptake and (3) identifying the potential additional Si sources to plants:

(1) The Si isotopes taken up by plants could theoretically follow either a Rayleigh model, implying that the Si source is limited (i.e., a closed system), or a steady-state model, implying a non-limited Si source and open system. The Rayleigh model could apply, for instance, to a pot experiment with no other Si supply than the initial hydroponic solution. In the case of Mule Hole, the intensity of soil mineral weathering (for instance, ASi or Na-plagioclase) varies seasonally based on soil moisture fluctuations. However, soil moisture hardly falls below $20 \%$ in the ferralsol and $25 \%$ in the vertisol (Parate et al., 2011), which is sufficient to sustain soil-Si release throughout the year. This soil-Si flux complements the Si flux from litter decay that regularly infiltrates the ground surface during the monsoon season. The continuous (but obviously temporally variable) supply of Si makes the soil a relatively open system with a non-limited source of $\mathrm{Si}$. As a consequence, a steady-state model would be more appropriate than the Rayleigh model to describe the silicon isotopic fractionation

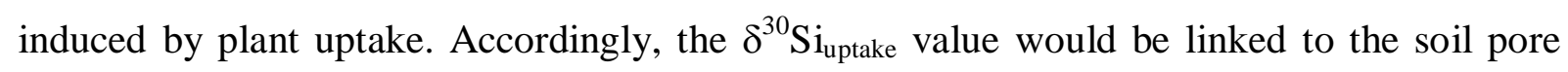
water composition by the following relation (De La Rocha et al., 1997):

$$
\delta^{30} S i_{\text {uptake }}=\delta^{30} S i_{\text {soil porewater }}+\Delta^{30} S i
$$


With $\underline{\underline{\Delta}}^{30} \mathrm{Si}$ being the isotopic fractionation factor between plants and solution. Although this parameter cannot be measured for a forest, it was measured for a few plants, such as rice (Ding et al. 2005) and banana (Opfergelt et al. 2006). Both plants exhibited the same $\underline{\underline{\Delta}}^{30} \mathrm{Si}_{\text {plant }}$ value of $-1 \%$. In this study, we assumed that this value applies to the silicon uptake of the

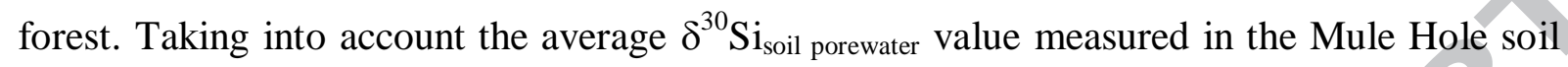
pore water, $1.64 \pm 0.11 \%$ o $(n=9)$, the $\delta^{30} \mathrm{Si}_{\text {uptake }}$ deduced from Eq. 3 would then be $0.64 \pm 0.11 \%$. This value is robust because the silicon isotopic composition of the deep soil pore water is homogeneous over space and time (Table 3). This confirms that the total Si uptake of the vegetation should be larger than the flux measured in the litter and that its $\delta^{30} \mathrm{Si}$ value should be enriched in light isotopes.

(2) Both the proportion of $\mathrm{Si}$ annually stored in the stem and its $\delta^{30} \mathrm{Si}$ value can be deduced from $\delta^{30} \mathrm{Si}_{\text {uptake }}$ and $\delta^{30} \mathrm{Si}_{\text {litter }}$ assuming that silicon isotopes, once taken up by trees, follow a classical Rayleigh fractionation model, as has been observed for some plants, such as rice (Ding et al., 2005), banana (Opfergelt et al., 2006), bamboo (Ding et al., 2008) and maize (Sun et al., 2017). Silica precipitation in the woody stem can be considered to be the cumulative product while the remaining fraction, which ends up in the leaves, can be considered to be the reactant. The $\delta^{30} \mathrm{Si}$ values of leaves are assimilated into the measured

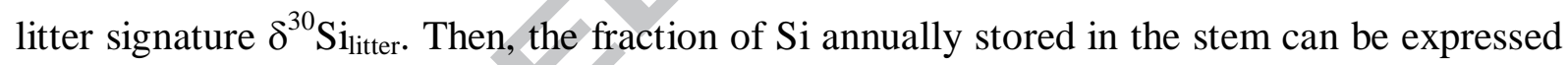
as:

$$
f_{\text {woody stem }}=1-f_{\text {litter }}=1-e^{\left(\frac{\delta^{30} S i_{\text {litter }}-\delta^{30} S i_{\text {uptake }}}{\Delta^{30} S i}\right)}
$$

Considering the abovementioned $\delta^{30} \mathrm{Si}_{\text {uptake }}$ and $\delta^{30} \mathrm{Si}_{\text {litter }}$, the fraction of $\mathrm{Si}$ that is annually stored in woody stem would be $0.46 \pm 0.02$, which accounts for almost as much as the litter flux. As a consequence, the overall Si taken up by vegetation would reach $4100 \mathrm{~mol} \mathrm{ha}^{-1} \mathrm{yr}^{-1}$, which is twice the value initially estimated from the solute elemental budget (Riotte et al.,

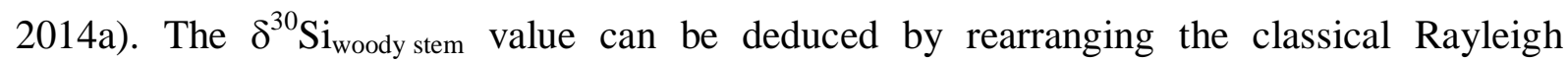
relationship:

$$
\delta^{30} S i_{\text {woody stem }}=\delta^{30} S i_{\text {uptake }}-\Delta^{30} S i \cdot f_{\text {litter }} \cdot \frac{\ln \left(f_{\text {litter }}\right)}{1-f_{\text {litter }}}
$$




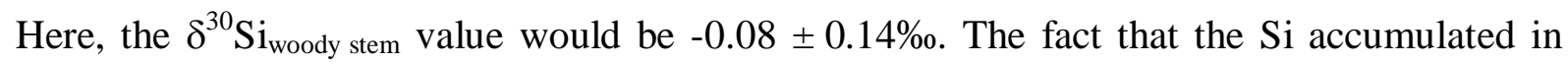
woody stems is isotopically lighter than that in the leaves is consistent with the progressive enrichment in ${ }^{30} \mathrm{Si}$ from the lowest parts of the plant (roots) to the highest ones (leaves) observed by Ding et al. (2005) and Opfergelt (2006).

(3) In the absence of additional proxies of silicate weathering fluxes or Si sources, one can only suggest hypotheses to explain the origin of the Si flux stored in the woody stem and its isotopic signature of $-0.08 \pm 0.14 \%$. If the $\mathrm{Si}$ source(s) consist(s) of a dissolved compartment, based on the above assumptions, its uptake should follow steady-state conditions, with a $\underline{\underline{\Delta}}^{30} \mathrm{Si}_{\text {plant }}$ value of $-1 \%$. The $\mathrm{Si}$ source should exhibit a $\delta^{30} \mathrm{Si}$ value of approximately $+1 \%$, which corresponds to the soil ASi (1.25\%o in ferralsols) and groundwater $(1.20 \pm 0.3 \%$; Table 3) signatures. The current stock of $4 \mathrm{~kg} \mathrm{ASi} \mathrm{m}^{-2}$ in the ferralsol could indeed sustain the additional flux of $1900 \mathrm{~mol} \mathrm{Si} \mathrm{ha}{ }^{-1} \mathrm{yr}^{-1}$ for 600 years (twice as long for vertisols). This pool was also recently identified as the principal Si source for rice (Riotte et al., 2017) and may thus sustain many $\mathrm{Si}$-accumulator plants. If plants directly take up $\mathrm{Si}$ from the soil compartments, with limited or no isotopic fractionation, then the $\delta^{30} \mathrm{Si}$ value of $-.08 \pm 0.14 \%$ in the stems could originate from the congruent dissolution of primary silicate minerals. The best rock-forming mineral candidates would be Al-poor phases, such as the ubiquitous $\mathrm{Mg}$ hornblende and quartz, because their weathering would not induce the formation of clay minerals and thus result in limited to no silicon isotopic fractionation. In all cases, the contribution of clay minerals as a source of Si to plants is unlikely. The isotopic solute budget of silica at the soil-plant scale is summarized in Fig. 5. 


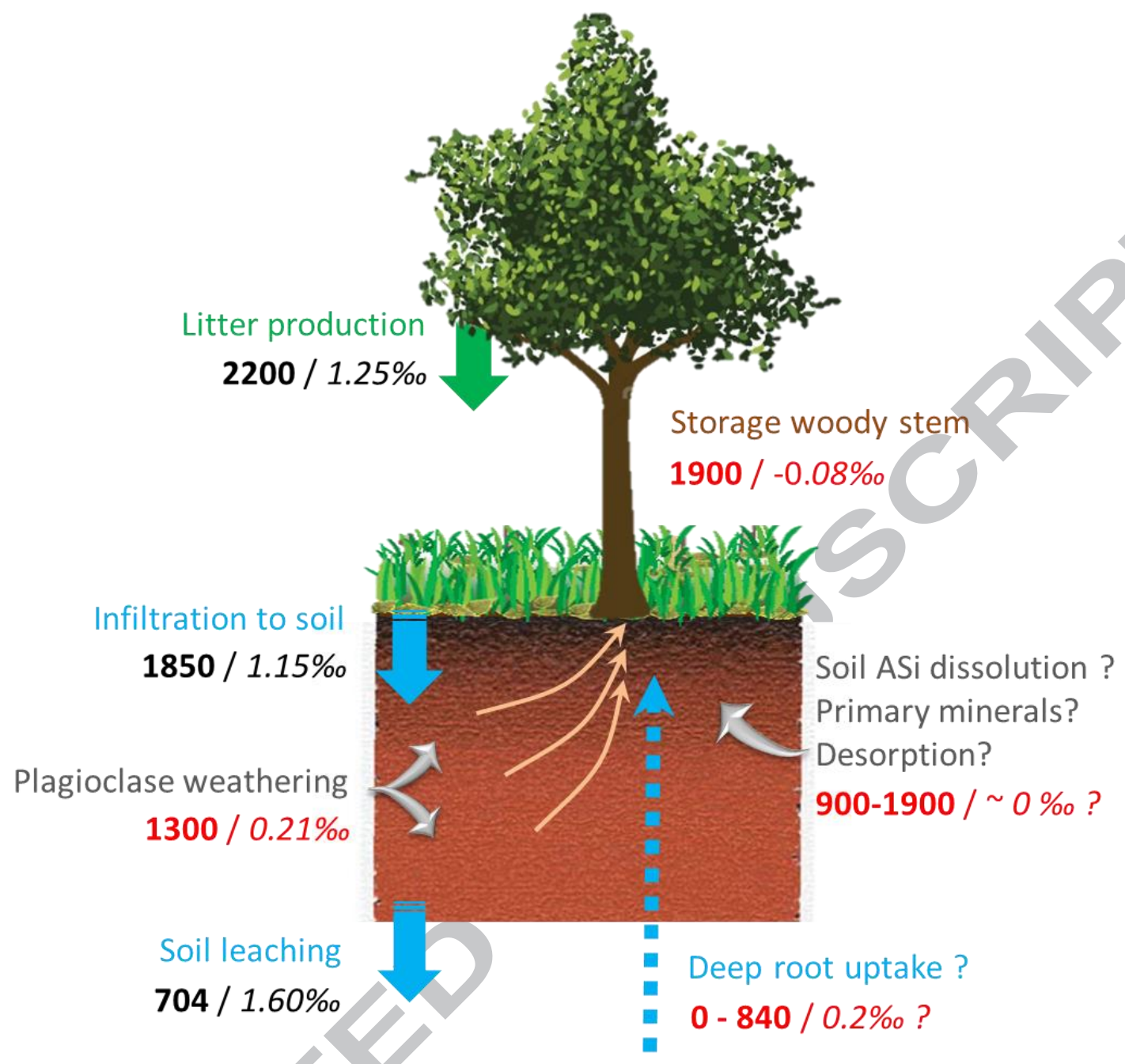

Fig. 5: Isotopic budget at the soil-plant scale in the Mule Hole watershed, with the annual Si flux (bold; in mol ha $\mathrm{yr}^{-1}$ ) and its $\delta^{30} \mathrm{Si}$ value (italic; in \%o) for each compartment. Values in black were measured; those in red were inferred from elemental and/or isotopic mass balance. This budget was performed in three steps: (1) primary isotopic budget based on the elemental Si budget from Riotte et al. (2014a), (2) deduction of woody stem storage that balances the plant budget of part 1, (3) additional fluxes from the soil layer needed to equilibrate the whole isotopic soil-plant budget. Blue text: DSi fluxes related to water fluxes. Grey text: DSi flux released from minerals (independent from water budget). Uncertainties given by Riotte et al. (2014a) for computed water fluxes (20\%) were used for the dissolved chemical fluxes. Uncertainty associated with the average measured litter flux is considered as the variability between the two measured years 2009 and 2010 (Riotte et al., 2014a).

To summarize the Si isotopic budget at the soil-plant scale, the $\delta^{30} \mathrm{Si}$ signatures of overland flow, soil pore water and litter confirm the biogenic origin of silica in the soil-percolating solutes and add a subsequent constraint to the elemental budget; the Si uptake by vegetation should be twice as large as the previous estimation, which was based on the elemental budget alone (Riotte et al., 2014a). 


\subsection{Controls of $\delta^{30}$ Si in stream dissolved and suspended loads}

The few studies that have reported time-related fluctuations of $\delta^{30} \mathrm{Si}$ in rivers have proposed various explanations. Hughes et al. (2013) observed that for several streams of the Amazon River system, the highest $\delta^{30} \mathrm{Si}$ values corresponded to base flow conditions and low $\mathrm{Si} /$ cation molar ratios. These compositions were interpreted to reflect the greater contribution of the chemical weathering of primary minerals due to a greater contribution of groundwater. The chemical compositions of these waters were compatible with either smectite (bisiallitization) or kaolinite (monosiallitization) production. In Siberian watersheds, the highest $\delta^{30} \mathrm{Si}$ occurred during the summer-fall season, when biomass and the active soil layer thickness increased. Two explanations were proposed to explain these high signatures, i.e., the formation of secondary minerals (clays and amorphous phases) or Si uptake by vegetation, although it was not possible to determine the respective contribution of each process (Pokrovsky et al., 2013). According to the hydrological model of the Mule Hole watershed (Violette et al., 2010b), the ephemeral stream is mostly fed by overland flow on ferralsol $\left(53 \mathrm{~mm} \mathrm{yr}^{-1}\right)$ and vertisol ( $29 \mathrm{~mm} \mathrm{yr}^{-1}$ ). Soil seepage contributes slightly to the runoff at the end of the rainy season, when soils are saturated $\left(12 \mathrm{~mm} \mathrm{yr}^{-1}\right)$. The relative contribution of each source is consistent with the evolution of the chemical composition during a given storm as well as during the rainy season (Riotte et al., 2014a).

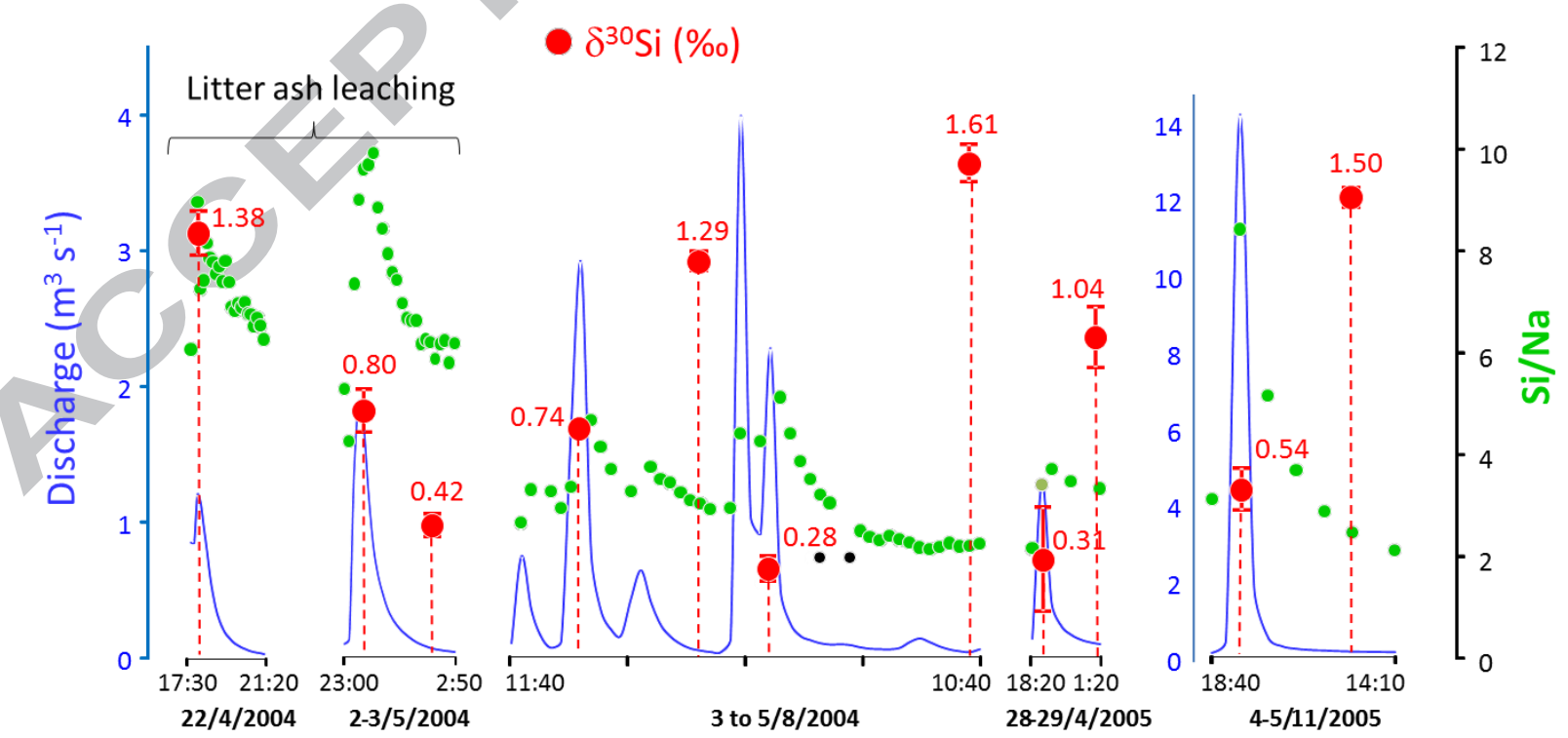

Fig. 6: Silicon isotopic composition of DSi in the Mule Hole stream during storms (values in red, in per mil). Green dots represent Si/Na molar ratios and blue lines represent the stream discharge (modified from Riotte et al., 2014a). 
Both the high $\delta^{30} \mathrm{Si}$ values and chemical compositions during flood recession reflect the contributions of soil seepage (Fig. 6), which is consistent with the expected water contributions in the stream (Violette et al., 2010b; Riotte et al., 2014a). Based on the isotopic mass balance at the soil-plant scale, it is possible to confidently assign the enrichment in the heavy Si isotopes of soil pore water, and then of flood recession, to the combination of both primary silicate chemical weathering and plant uptake.

Various processes have been suggested to explain the low $\delta^{30} \mathrm{Si}$ values in rivers. In the Amazon Basin, the lowest $\delta^{30} \mathrm{Si}$ values were found in the plain (Rio Negro) and attributed to an increase in the relative silica mobility $\left(f_{\mathrm{Si}}\right)$, defined by the ratio of the $\mathrm{Si} /\left(\mathrm{Na}^{*}+\mathrm{K}^{*}\right)$ molar ratio of the dissolved phase ( $\mathrm{Na}$ and $\mathrm{K}$ corrected from atmospheric inputs) divided by the same ratio of the bedrock (Hughes et al., 2013). According to these authors, the silicate bedrock would dissolve in a congruent way, i.e., with a limited fraction of isotopically light $\mathrm{Si}$ relocated to secondary clay minerals (kaolinite). Most of the $\delta^{30} \mathrm{Si}$ values of the large rivers of the Amazonian basin were indeed inversely correlated to $f_{\mathrm{Si}}$, which was compatible with Rayleigh or steady-state fractionation models. Such findings are consistent with those of Frings et al. (2015), who used a similar proxy in the Ganga Basin, and Georg et al. (2007) in Iceland, who used the ratio between DSi and $\mathrm{Na}$ as a silica mobility index. In both cases, the role of vegetation in the $\delta^{30} \mathrm{Si}$ values of rivers was considered to be unlikely. However, neglecting the role of vegetation in the case of the Amazon plain is surprising, as it is covered by a dense forest, in which silica recycling by litter accounts for up to $1500 \mathrm{~mol} \mathrm{ha}^{-1} \mathrm{yr}^{-1}$ (Cornu et al., 1998). According to our observations at Mule Hole, the high $\mathrm{K}^{*} / \mathrm{Na}^{*}$ values associated with the low $\delta^{30} \mathrm{Si}$ values in the Amazonian rivers (Hughes et al., 2013) could also result from the contribution of vegetation cycling. Very low $\delta^{30} \mathrm{Si}$ values (close to $0 \%$ o) were also observed in the black rivers of the Congo Basin and interpreted to represent the dissolution of clay minerals by organic-rich waters (Cardinal et al., 2010). In Siberian watersheds, the low $\delta^{30} \mathrm{Si}$ values during spring floods $(0.8 \%)$ were assigned to the partial dissolution of the silicate suspended load because of the high solid/solution ratio (Pokrovsky et al., 2013). During the flow peaks of Mule Hole, the stream $\delta^{30} \mathrm{Si}$ is also low $(0.47$ $\pm 0.22 \%$ ) and surprisingly lighter than the overland flow signature $(1.15 \pm 0.53 \%$ o. This is unexpected since the stream is fed by overland flow during flow peaks. An additional DSi source to the stream is needed. As this DSi source should exhibit a low $\delta^{30} \mathrm{Si}$ value, it could correspond to the dissolution of the suspended load, as proposed by Pokrovsky et al. (2013) for Siberian rivers. However, the average DSi concentration during these flow peaks 
$\left(128 \pm 35 \mu \mathrm{mol} \mathrm{L}{ }^{-1}\right)$ exceeds saturation with respect to kaolinite and smectite, thus making clay dissolution unlikely. Moreover, the circum-neutral $\mathrm{pH}$ and low DOC content of the stream do not favour clay mineral dissolution. An alternative explanation could be partial, short-term (i.e., hourly) phytolith dissolution within the stream which, according to ash leaching experiments (see section 4.3), could release light $\mathrm{Si}$ isotopes. If the $\delta^{30} \mathrm{Si}$ value of the additional DSi source were $-1 \%$, it would contribute to up to $30 \%$ of stream DSi, which is unlikely because ash leaching experiments indicate that the kinetic isotopic fractionation that releases light $\mathrm{Si}$ isotopes is expected to occur during incipient ASi dissolution (see Fig. 4). Sampling bias thus remains the most likely cause of the difference between the $\delta^{30} \mathrm{Si}$ values of the overland flow and streams.

The ASi flux exported annually by the stream as suspended load was estimated using the 2003-2014 specific runoff of $100 \mathrm{~mm} \cdot \mathrm{yr}^{-1}$, the average suspended load content of $0.5 \mathrm{~g} \mathrm{~L}^{-1}$ and the average suspended load $\mathrm{ASi}_{\mathrm{zb}}$ concentration of $0.44 \%$. The ASi specific flux exported accounts for $89 \mathrm{~mol} \mathrm{ha}^{-1} \mathrm{yr}^{-1}$, which represents only $4 \%$ of the annual flux produced by litter fall; this is in good agreement with the data from the Kaveri River, India (Meunier et al., 2015). This also confirms that the silica mobilized by the vegetation at Mule Hole is rarely exported as ASi but is rather accumulated or recycled within the watershed (Riotte et al., 2014a). However, the specific ASi flux exported by the stream is close to the DSi flux for the period 2005-2009 of $130 \mathrm{~mol} \mathrm{ha}^{-1} \mathrm{yr}^{-1}$ (Riotte et al., 2014a). Similarities in the exported ASi and DSi were also recently observed in the Ganga River (Frings et al., 2014b) and represent further evidence that biota play a significant role in the export of silica to the ocean.

\section{Conclusion}

The investigation of silicon isotopic fractionation during water-rock/soil-plant interactions in the forested watershed of Mule Hole provided new constraints on the biogeochemical cycling of silica in this dry tropical forest:

- The $\delta^{30} \mathrm{Si}$ composition of amorphous Si in litter (tree leaves and grass), surface soil horizons and the ferralsol profile is particularly homogeneous, with a range of only 1.1 to $1.4 \%$. The only exceptions are deeper horizons from the vertisol profile (in a marginal area of the watershed) that also contain pollen taxa typical of humid forests. Phytoliths from these horizons may thus be representative of past, more humid conditions. The homogeneity of the $\delta^{30} \mathrm{Si}$ values in ASi confirms that the silicon isotope signature of 
vegetation is "system-dependent". Accordingly, $\delta^{30} \mathrm{Si}$ should be suitable for tracing the biogenic component of silica cycling at both the soil-plant and watershed scales.

- At the soil-plant scale, the $\delta^{30} \mathrm{Si}$ value of solutes percolating into the soil is similar to the isotopic signature of phytoliths, which supports the biogenic origin of DSi in the soil input. Within the soil, the assignment of $\delta^{30} \mathrm{Si}$ signatures to the solute elemental budget suggests an imbalance. The isotopic equilibration of the solute budget, considering a steady-state model for plant uptake and Rayleigh fractionation within the plants, implies a silica flux annually taken up by vegetation that is twice as large as that first estimated from the elemental budget (Riotte et al., 2014a). This additional Si flux, which may be stored in woody stems, should exhibit a $\delta^{30} \mathrm{Si}$ value close to $0 \%$. Such a signature could be compatible with soil ASi dissolution or deep root uptake if a steady-state model applies. If vegetation takes up Si directly from soil particles without isotopic fractionation, then primary silicate or Si desorption from clays could constitute possible sources. We observed that deep groundwater exhibits the same signature as litter dissolution, meaning that biotic (cycling through vegetation) and abiotic (silicate chemical weathering) reactions may lead to comparable $\delta^{30} \mathrm{Si}$ signatures.

- Ephemeral stream storms tend to display low $\delta^{30} \mathrm{Si}$ values during peak flows, whereas high $\delta^{30} \mathrm{Si}$ values are observed during recessions, but only at the end of the rainy season, when soils are saturated. This pattern has been observed in most previous river studies. The chemical and isotopic compositions of stream recessions tend consistently towards soil pore water compositions, in agreement with the hydrological functioning of such an ecosystem. However, a slight difference was observed between the $\delta^{30} \mathrm{Si}$ values of overland flow, which feeds the stream during flood peaks, and those of the stream. The contribution of clay mineral dissolution from the suspended load is unlikely, given the DSi concentration in the stream. We suggest that this slight difference results from a bias in overland flow sampling.

As a broader conclusion, it appears that stable silicon isotope fractionation provides significant insights into the processes controlling the biogeochemical cycle of silica in ecosystems, but only if water and elemental mass balances are already well constrained.

\section{Acknowledgments}


The Mule Hole basin is part of the ORE-BVET project (Observatoire de Recherche en Environnement - Bassin Versant Expérimentaux Tropicaux, http://bvet.omp.obsmip.fr/index.php/eng/) supported by the French Institute of Research for Development (IRD), CNRS and Toulouse University. The project also benefited from funding from INSU/ CNRS (Institut National des Sciences de l'Univers/Centre National de la Recherche Scientifique) through the French program EC2CO (Ecosphère Continentale et Côtière) and from the ACIEau. The authors are thankful to the Associate Editor, Jan Wiederhold, to Sophie Opfergelt and the two anonymous reviewers for their numerous comments and corrections that greatly improved the quality of the manuscript. Sebastien Carretier and Vincent Regard are thanked for their help in calculations of error propagation. We thank the Karnataka Forest Department and the staff of the Bandipur National Park for all the facilities and support they provided. 


\section{Figure \& tables captions}

Figure 1: The Mule Hole watershed with soil and vegetation map, showing the sampling location of composite soils (plots A, B, C, D; see text for description), soil profiles, overland flow and ground water (modified from Riotte et al., 2014a). ATT (medium green): Anogeissus - Tectona - Terminalia facies. Dark green: swamp facies; light green: Shorea facies.

Figure 2: Phytolith morphotypes and diatom contents in suspended load and soils of Mule Hole. ATT $=$ Anogeissus - Tectona - Terminalia facies. ND = non-diagnostic .

Figure 3: Influence of purity on $\delta^{30} \mathrm{Si}$ signatures in the $\mathrm{ASi}_{\mathrm{zb}}$ fractions of surface soils, soil profiles and suspended load in Mule Hole. Purity index is defined as (Si$(\mathrm{Al}+\mathrm{Fe}+\mathrm{Ca}+\mathrm{Mg}+\mathrm{Mn}, \mathrm{K})) / \mathrm{Si}$. Purity index values of fresh litter and clays are theoretical. $\mathrm{OF}=$ overland flow. This diagram shows that despite being apparently pure under microscope, the ASi fraction separated by dense liquor can still contain significant amounts of impurities that can impact the $\delta^{30} \mathrm{Si}$ signature of this fraction. Correcting for impurities allows us to recover the $\delta^{30} \mathrm{Si}$ value of the pure ASi fraction.

Figure 4: Evolution of $\delta^{30} \mathrm{Si}$ in the dissolved phase of ash leaching experiments with the percentage of dissolved litter-Si (fraction of Si release divided by the total Si content in the bulk litter). Grey area: range of phytolith compositions found in this study. Open circles: phytolith dissolution experiments from Ziegler et al. (2005), with dotted line representing the isotopic composition of the phytolith.

Figure 5: Isotopic budget at the soil-plant scale in the Mule Hole watershed, with the annual Si flux (bold; in mol ha $\mathrm{yr}^{-1}$ ) and its $\delta^{30} \mathrm{Si}$ value (italic; in \%o) for each compartment. Values in black were measured, those in red were inferred from elemental and/or isotopic mass balance. This budget was performed in three steps: (1) primary isotopic budget based on the elemental Si budget from Riotte et al. (2014a), (2) deduction of woody stem storage that balances the plant budget of part 1, (3) additional fluxes from the soil layer needed to equilibrate the whole isotopic soil-plant budget. Blue text: DSi fluxes related to water fluxes. Grey text: DSi flux released from minerals (independent from water budget). Uncertainties given by Riotte et al. (2014a) for computed water fluxes $(20 \%)$ were used for the dissolved chemical fluxes. Uncertainty associated with the average measured litter flux is considered as the variability between the two measured years 2009 and 2010 (Riotte et al., 2014a).

Figure 6: Silicon isotopic composition of DSi in the Mule Hole stream during storms (values in red, in per mil). Green dots represent $\mathrm{Si} / \mathrm{Na}$ molar ratio and blue lines represent the stream discharge (modified from Riotte et al., 2014a). 


\section{References}

Abraham K., Opfergelt S., Fripiat F., Cavagna A., de Jong J., Foley S., André L. and Cardinal

D. $(2008){ }^{30} \mathrm{Si}$ and ${ }^{29} \mathrm{Si}$ Determinations on USGS BHVO-1 and BHVO-2 Reference Materials with a New Configuration on a Nu Plasma Multi-Collector ICP-MS. Geostand. Geoanal. Res. 32, 193-202.

Alexandre A., Meunier J.D., Colin F., Koud J.M. (1997) Plant impact on the biogeochemical cycle of silicon and related weathering processes. Geochim. Cosmochim. Acta, 61, 677-682.

Alexandre A., Bouvet M., Abbadie L., (2011) The role of savannas in the terrestrial Si cycle: a case-study from Lamto, Ivory Coast. Global Planet. Changes 78, 162-169.

Ameijeiras-Mariño Y., Opfergelt S., Schoonejans J., Vanacker V., Sonnet P., de Jong J., Delmelle P. (2017) Impact of low denudation rates on soil chemical weathering intensity: A multiproxy approach. Chem. Geol., 456, 72-84.

Anupama K., S. Prasad, C. S. Reddy (2014) Vegetation, land cover and land use changes of the last 200 years in the Eastern Ghats (southern India) inferred from pollen analysis of sediments from a rain-fed tank and remote sensing. Quat. Int. 325, 93-104.

Audry S., Akerman A., Riotte J., Oliva P., Maréchal J.C., Fraysse F., Pokrovsky O., Braun J.J. (2014) Contribution of forest fire ash and plant litter decay on stream dissolved composition in a sub-humid tropical watershed (Mule Hole, Southern India). Chem. Geol. 372, 144-161.

Baram S., Ronen Z., Kurtzman D., Külls C., Dahan O. (2013) Desiccation-crack-induced salinization in deep clay sediment, Hydrol. Earth Syst. Sci., 17, 1533-1545.

Barbiero L., Parate H. R., Descloitres M., Bost A., Furian S., Mohan Kumar M. S., Kumar C. and Braun J. J. (2007) Using a structural approach to identify relationships between soil and erosion in a semi-humid forested area, South India. Catena 70, 313-329.

Barbiero L., Mohan Kumar M.S., Violette A., Oliva P., Braun J.J., Kumar C., Furian S., Babic M., Riotte J., Valles V. (2010) Soil transformations through ferrolysis induced by recent natural drainage in Vertisols of 1 sub-humid South India. Geoderma 156, 173-188.

Barboni D., R. Bonnefille (2001) Precipitation signal in pollen rain from tropical forests, South India. Rev. Palaeobot. Palynol. 114, 239-258. 
Barboni D., R. Bonnefille, S. Prasad, B. R. Ramesh (2003) Variation in modern pollen from tropical evergreen forests and the monsoon seasonality gradient in SW India. J. Veg. Sci. 14, $551-562$.

Bartoli F. and Wilding L.P. (1980) Dissolution of biogenic opal as a function of its physical and chemical pool in the terrestrial silicon cycle. Nature 433, 399-402.

Blecker S.W., McCulley R. L., Chadwick O. A., and Kelly E. F. (2006) Biologic cycling of silica across a grassland bioclimosequence. Global Biogeochem. Cycles, 20, doi:10.1029/2006GB002690.

Bouchez J., von Blanckenburg F., A. Schuessler J. (2013) Modeling novel stable isotope ratios in the weathering zone. Am. J. Sci. 313, 267-308.

Braun J.J., Descloitres M., Riotte J., Fleury S., Barbiero L., Boeglin J.L., Violette A., Lacarce E., Ruiz L., Sekhar M., Mohan Kumar M.S., Subramanian S., Dupré B. (2009) Regolith mass balance inferred from combined mineralogical, geochemical and geophysical studies: Mule Hole gneissic watershed, South India. Geochim. Cosmochim. Acta 73, 935-961.

Braun, J.-J., Riotte, J., Battacharya, S., Violette, A., Prunier, J., Bouvier, V., Candaudap F., Maréchal J.C., Ruiz L., Rekha Panda S., Subramanian, S. (2017) REY-Th-U solute dynamics in the critical zone: Combined influence of chemical weathering, atmospheric deposit leaching, and vegetation cycling (mule hole watershed, South India). Geochem., Geophys., Geosys., 18. https://doi.org/10.1002/2017GC007158

Cardinal D., Gaillardet J., Hughes H. J., Opfergelt S. and André L. (2010) Contrasting silicon isotope signatures in rivers from the Congo Basin and the specific behaviour of organic - rich waters. Geophys. Res. Lett. 37, doi:10.1029/2010GL043413.

Cary L., Alexandre A., Meunier J.D., Boeglin J.L., Braun J.J. (2005) Contribution of phytoliths to the suspended load of biogenic silica in the Nyong basin rivers (Cameroon). Biogeochem.74, 101-114.

Collura L. V., K. Neumann, (2016) Wood and bark phytoliths of West African woody plants. Quat. Intern. http://dx.doi.org/10.1016/j.quaint.2015.12.070

Cornelis and Delvaux (2016) Soil processes drive the biological silicon feedback loop. Funct. Ecol. 30, 1298-1310. doi: 10.1111/1365-2435.12704

Cornu S., Lucas Y., Ambrosi J. P. and Desjardins T. (1998) Transfer of dissolved Al, Fe and Si in two amazonian forest environments in Brazil. Eur. J. Soil Sci. 49, 377-384. 
De La Rocha, C.L., Brzezinski, M.A., DeNiro, M.J., 1997. Fractionation of silicon isotopes by marine diatoms during biogenic silica formation. Geochim. Cosmochim. Acta 61, 50515056.

Delstanche S., Opfergelt S. Cardinal D. Elsass F. André L., Delvaux L. (2009) Silicon isotopic fractionation during adsorption of aqueous monosilicic acid onto iron oxide. Geochim. Cosmochim. Acta, 73, 923-934.

Demarest M.S., Brzezinski M.A., Beucher C.P. (2009) Fractionation of silicon isotopes during biogenic silica dissolution. Geochim. Cosmochim. Acta, 73, 5572-5583.

Derry L.A., Kurtz A.C., Ziegler K. and Chadwick O.A. (2005) Biological control of terrestrial silica cycling and export fluxes to watersheds. Nature, 433, 728-731.

Ding T., Ma G., Shui M., Wan D. and Li R. (2005) Silicon isotope study on rice plants from the Zhejiang province, China. Chem. Geol. 218, 41-50.

Ding T.P., Zhou J.X., Wan D.F., Chen Z.Y., Wang C.Y., Zhang F. (2008) Silicon isotope fractionation in bamboo and its significance to the biogeochemical cycle of silicon. Geochim. Cosmochim. Acta, 72, 1381-1395.

Dupuis R., Benoit M., Nardin E., Meheut M. (2015) Fractionation of silicon isotopes in liquids: The importance of configurational disorder. Chem. Geol., 396, 239-254.

Engström E., Rodushkin I., Öhlander B., Ingri J., Baxter D.C. (2008) Silicon isotopic composition of boreal forest vegetation in Northern Sweden. Chem. Geol., 257, 247-256.

Engström E., Rodushkin I., Ingri J., Baxter D.C., Ecke F., Österlund H. and Öhlander B. (2010) Temporal isotopic variations of dissolved silicon in a pristine boreal river. Chem. Geol. 271, $\overline{142}-152$

Faegri K., Iversen J., Kaland P.E., Krzywinski K. (1991) Text Book of Pollen Analysis (fourth ed.) John Wiley and Sons Ltd, 328p.

Fraysse F., Pokrovsky O.S. and Meunier J.D. (2010) Experimental study of terrestrial plant litter interaction with aqueous solutions. Geochim. Cosmochim. Acta 74, 70-84.

Frings P. J., De La Rocha C., Struyf E., van Pelt D., Schoelynck J., Hudson J.M., Gondwe M. J., Wolski P., Mosimane K., Gray W., Schaller J., Conley D.J. (2014a) Tracing silicon cycling in the Okavango Delta, a sub-tropical flood-pulse wetland using silicon isotopes Geochim. Cosmochim. Acta, 142, 132-148.

Frings P.J., Clymans W., Conley D.J. (2014b) Amorphous silica transport in the Ganges basin: Implications for Si delivery to the oceans. Proc. Earth Planet. Sci. 10, 271-274. 
Frings P.J., Clymans W., Fontorbe G., Gray W., Chakrapani G.J., Conley D.J., De La Rocha C.L. (2015) Silicate weathering in the Ganges alluvial plain. Earth Planet. Sci. Lett. 427, 136148.

Frings P.J., Clymans W., Fontorbe G., De La Rocha C., Conley D.J. (2016) The continental Si cycle and its impact on the ocean Si isotope budget. Chem. Geol. 425, 12-36.

Geilert S., Vroon P.Z., Roerdink D.L., Van Cappellen P., van Bergen M.J. (2014) Silicon isotope fractionation during abiotic silica precipitation at low temperatures: Inferences from flow-through experiments. Geochim. Cosmochim. Acta 142, 95-114.

Georg R.B., Reynolds B.C., Frank M. and Halliday A.N. (2006) Mechanisms controlling the silicon isotopic compositions of river waters. Earth Planet. Sci. Lett. 249, 290-306.

Georg R.B., Reynolds B.C., West A.J., Burton K.W., Halliday A.N. (2007) Silicon isotope variations accompanying basalt weathering in Iceland. Earth Planet. Sci. Lett. 261, 476-490.

Gunnarsson I. and Arnorsson S. (2000) Amorphous silica solubility and the thermodynamic properties of $\mathrm{H}_{4} \mathrm{SiO}_{4}$ in the range of 0 to $350{ }^{\circ} \mathrm{C}$ at $\mathrm{P}_{\text {sat. Geochim. Cosmochim. Acta } 64,2295-}$ 2307.

Huang T.C. (1972) Pollen Flora of Taiwan. National Taiwan University Botany Department Press.

Hughes H. J., Sondag F., Cocquyt C., Laraque A., Pandi A., André L., Cardinal D. (2011) Effect of seasonal biogenic silica variations on dissolved silicon fluxes and isotopic signatures in the Congo River. Limnol. Oceanogr., 56, 551-561.

Hughes H. J., Sondag F., Santos R. V., André L., Cardinal D. (2013) The riverine silicon isotope composition of the Amazon Basin. Geochim. Cosmochim. Acta 121, 637-651.

ICPN Working Group, M. Madella, A. Alexandre, T. Ball, (2005) International Code for Phytolith Nomenclature 1.0. Ann Bot. 96, 253-260.

Jouquet P., Caner L., Bottinelli N., Chaudhary E., Cheik S., Riotte J. (2017) Where do southIndian termite mound soils come from? Appl. Soil Ecol. 117-118, 190-195.

Kelly E.F. (1990) Method for Extracting Opal Phytoliths from Soil and Plant Material. Intern. Rep. Dep. Agron. Colorado State Univ., Fort Collins.

Kjaer E.D., Kajornsrichon S. and Lauridsen E. B. (1999) Heartwood, Calcium and Silica Content in Five Provenances of Teak (Tectona grandis L.) Silvae Genetica 48(1), 1-3. 
Krishnan S., N. P. Samson, P. Ravichandran, D. Narasimhan, P. Dayanandan (2000) Phytoliths of Indian grasses and their potential use in identification. Botanical Journal of the Linnean Society. 132, 241-252.

Louvat P. and Allegre C.J. (1997) Present day denudation rates on the island of Réunion determined by river geochemistry: basalt weathering and mass budget between chemical and mechanical erosions. Geochim. Cosmochim. Acta 61, 3645-3669.

Lucas Y., Luizão F.J., Chauvel A., Rouiller J., Nahon D. (1993) The relation between biological activity of the rainforest and mineral composition of the soils. Science 260, 521-23.

Lucas Y. (2001) The role of plants in controlling rates and products of weathering: Importance of Biological pumping. Annu. Rev. Earth Planet. Sci. 29, 135-163.

Madella M., Alexandre A., Ball T. (2005) International Code for Phytolith Nomenclature 1.0. Ann. Bot. 96, 253-260.

Maréchal J.C., Murari R.R.V., Riotte J., Vouillamoz J.M., Mohan Kumar M.S., Ruiz L., Muddu S. and Braun J.J. (2009) Indirect and direct recharges in a tropical forested watershed: Mule Hole, India. J. Hydrol. 364, 272-284.

Maréchal J.C., Riotte J., Lagane C., Subramanian S., Kumar C., Ruiz L., Audry S., Murari V., Braun J.J. (2011) Chemical groundwater outputs from a small drainage watershed: Mule Hole, South India. Appl. Geochem. 26, S94-S96.

Martin J.M. and Meybeck M. (1979) Elemental Mass-Balance of Material Carried by Major World Rivers. Mar. Chem. 7, 173-206.

Méheut M., Schauble E.A. (2014) Silicon isotope fractionation in silicate minerals: Insights from first-principles models of phyllosilicates, albite and pyrope. Geochim. Cosmochim. Acta, 134, $137-154$

Meunier J.D., Alexandre A., Colin F., Braun J.J. (2001) Intérêt de l'étude du cycle biogéochimique du silicium pour interpréter la dynamique des sols tropicaux. Bull. Soc. Geol. Fra. 172, 533-538.

Meunier J. D., Keller C., Guntzer F., Riotte J., Braun J.J., Krishnamurty A. (2014) Assessment of the $1 \% \mathrm{Na}_{2} \mathrm{CO}_{3}$ technique to quantify the phytolith pool. Geoderma, 216, 3035.

Meunier J.D., Riotte J., Braun J.J., Muddu S., Chalié F., Barboni D. Saccone L. (2015) Controls of DSi in streams and reservoirs along the Kaveri River, South India. Sci. Tot. Env. 502, 103-113. 
Moore P.D., Webb J.A., Collinson M.E. (1991) Pollen Analysis (second ed.) Blackwell Scientific Publications, 216 p.

Nayar T.S. (1990) Pollen Flora of Maharashtra State, India. Today and Tomorrow's Printers and Publishers, New Delhi, 157 p.

Nesbitt H. W. and Young G. M. (1982) Early Proterozoic climates and plate motions inferred from major element chemistry of lutites. Nature 299, 715-717.

Opfergelt S., Cardinal D., Henriet C., Draye X., André L., Delvaux B. (2006) Silicon isotopic fractionation by banana (Musa spp.) grown in a continuous nutrient flow device. Plant Soil 285, 333-345.

Opfergelt S., de Bournonville G., Cardinal D., André L., Delstanche S., Delvaux B. (2009) Impact of soil weathering degree on silicon isotopic fractionation during adsorption onto iron oxides in basaltic ash soils, Cameroon. Geochim. Cosmochim. Acta, 73, 7226-7240.

Opfergelt S., Georg R.B., Delvaux B., Cabidoche Y.M., Burton K.W., Halliday A.N. (2012) Silicon isotopes and the tracing of desilication in volcanic soil weathering sequences, Guadeloupe. Chem. Geol. 326-327, 113-122.

Opfergelt S. and Delmelle P. (2012) Silicon isotopes and continental weathering processes: Assessing controls on Si transfer to the ocean. C. R. Geoscience 344, 723-738.

Parate H.R., M. S. Mohan Kumar, Descloitres M., Barbiero L., Ruiz L., Braun J.J., M. Sekhar and C. Kumar (2011) Comparison of electrical resistivity by geophysical method and neutron probe logging for soil moisture monitoring in a forested watershed. Curr. Sci., 100, 14051412.

Parker A. (1970) An index of weathering for silicate rocks. Geol. Mag., 501-504.

Parkhurst D.L. and Appelo C.A.J. (1999) User's guide to PHREEQC (Version 2)-A computer program for speciation, batch-reaction, one-dimensional transport, and inverse geochemical calculations. US Geological Survey Water-Resources Investigations Report.

Piperno D. R. (2006) Phytoliths: A Comprehensive Guide for Archaeologists and Paleoecologists. Rowman Altamira. 238p.

Poitrasson F. and Zambardi T. (2015) An Earth-Moon silicon isotope model to track silicic magma origins. Geochim. Cosmochim. Acta, 167, 301-312.

Poitrasson, F. (2017) Silicon isotope geochemistry. In: Teng, F.Z., Watkins, J.M., Dauphas, N. (Eds.), Non-traditional stable isotopes. Rev. in Min. Geochem. Mineralogical Society of America, Washington, D.C., 289-344. 
Pokrovsky O.S., Reynolds B.C., Prokushkin A.S., Schott J., Viers J. (2013) Silicon isotope variations in Central Siberian rivers during basalt weathering in permafrost-dominated larch forests. Chem. Geol. 355, 103-116.

Riotte J., Maréchal J.C., Audry S., Kumar C., Bedimo J.P., Ruiz L., Sekhar M., Cisel M., Chitra Tarak R., Varma M.R.R., Lagane C., Reddy P. and Braun J.J. (2014a) Vegetation impact on stream chemical fluxes: Mule Hole watershed (South India). Geochim. Cosmochim. Acta 145, 116-138.

Riotte J., Ruiz L., Audry S., Sekhar M., Mohan Kumar M.S., Siva Soumya B. and Braun J.J. (2014b) Impact of vegetation and decennial rainfall fluctuations on the weathering fluxes exported from a dry tropical forest (Mule Hole). Proc. Earth Planet. Sci. 10, 34-37.

Riotte J., Sandhya K., Prakash N.B., Audry S., Zambardi T., Chmeleff J., Buvaneshwari S., Meunier J.D. (2017) Origin of silica in rice plants and contribution of diatom earth fertilization: insights from isotopic Si mass balance in a paddy field. Plant and Soil. DOI: 10.1007/s11104-017-3535-z

Ruiz L., Varma M.R.R., Mohan Kumar M.S., Sekhar M., Maréchal J.C., Descloitres M., Riotte J., and Braun J.J. (2010) Water balance modelling in a tropical watershed under deciduous forest (Mule Hole, India): regolith matric storage buffers the groundwater recharge process. J. Hydrol., 380, 460-472.

Saccone L., Conley D.J., Koning E., Sauer D., Sommer M., Kaczorek D., Blecker S.W., Kelly E.F. (2007) Assessing the extraction and quantification of amorphous silica in soils of forest and grassland ecosystems. Eur. J. Soil Sci. 58, 1446-1459.

Saccone L., Conley D.J., Likens G.E., Bailey S.W., Buso D.C., Johnson C.E. (2008) Factors that Control the Range and Variability of Amorphous Silica in Soils in the Hubbard Brook Experimental Forest. Soil Sci. Soc. Am. J., 72, 1637-1644.

Savage P.S., Georg R.B., Williams H.M., Turner S., Halliday A.N. and Chappell B.W. (2012) The silicon isotope composition of granites. Geochim. Cosmochim. Acta, 92, 184-202.

Savage P.S., Armytage R.M.G., Georg R.B., Halliday A.N. (2014) High temperature silicon isotope geochemistry. Lithos 190-191, 500-519.

Shadakshara Swamy N., Jayananda M. and Janardhan A. S. (1995) Geochemistry of Gundlupet gneisses, Southern Karnataka: a 2.5 Ga old reworked sialic crust. In: Yoshida, M., Santosh, M., and Rao, A. T. Eds.), India as a fragment of East Gondwana. Gondwana Research Group. 
Steinhoefel G., Breuerb J. , von Blanckenburg F., Hornc I., Sommer M. (2017) The dynamics of Si cycling during weathering in two small catchments in the Black Forest (Germany) traced by $\mathrm{Si}$ isotopes. Chem. Geol., 466, 389-402.

Sun Y., Wu L., Li X., Sun L., Gao J., Ding T., Zhu Y. (2017) Silicon Isotope Fractionation in Maize and its Biogeochemical Significance. Anal. Lett. 50, 2475-2490.

Sun Y., Wu L. H., Li X. (2016) Experimental Determination of Silicon Isotope Fractionation in Rice. PLoS ONE 11(12): e0168970. doi:10.1371/journal.pone.0168970.

Tissot C., Chikhi H., Nayar T.S. (1994) Pollen of Wet Evergreen Forests of the Western Ghats, India. Publications du departement d'ecologie, Institut Francais de Pondichery, 133p.

Treguer P.J., De La Rocha C.L. (2013) The World Ocean Silica Cycle. In: Carlson, C.A., Giovannoni, S.J. (Eds.), Annual Review of Marine Science, 5. Annual Reviews, Palo Alto, 477-501.

Vasanthy G. (1976) Pollen of the South Indian Hills, Institut Francais de Pondichery (1976), $74 p$.

Violette A., Riotte J., Braun J.J., Oliva P., Maréchal J.C., Sekhar M., Jeandel C., Subramanian S., Barbiero L. and Dupré B. (2010a) Formation and preservation of pedogenic carbonates in South India, links with paleomonsoon and pedological conditions: Clues from Sr isotopes, U-Th series and REEs, Geochim. Cosmochim. Acta 74, 7059-7085.

Violette A., Goddéris G., Maréchal J.M., Riotte J., Oliva P., Mohan Kumar M.S., Sekhar M., Braun J.J. (2010b) Modeling the chemical weathering fluxes at the watershed scale in the Tropics (Mule Hole, South India): Relative contribution of the smectite/kaolinite assemblage versus primary minerals. Chem. Geol. 277, 42-60.

Wetzel F., de Souza G.F., Reynolds B.C. (2014) What controls silicon isotope fractionation during dissolution of diatom opal? Geochim. Cosmochim. Acta, 131, 128-137.

Zambardi T. and Poitrasson F. (2011) Precise Determination of Silicon Isotopes in Silicate Rock Reference Materials by MC-ICP-MS. Geostandards and Geoanalytical Research, 35, 89-99.

Ziegler K., Chadwick O.A., Brzezinski M.A. and Kelly E.F. (2005) Natural variations of $\delta^{30} \mathrm{Si}$ ratios during progressive basalt weathering, Hawaiian Islands. Geochim. Cosmochim. Acta 69 , 4597-4610. 


\section{Figure 1}

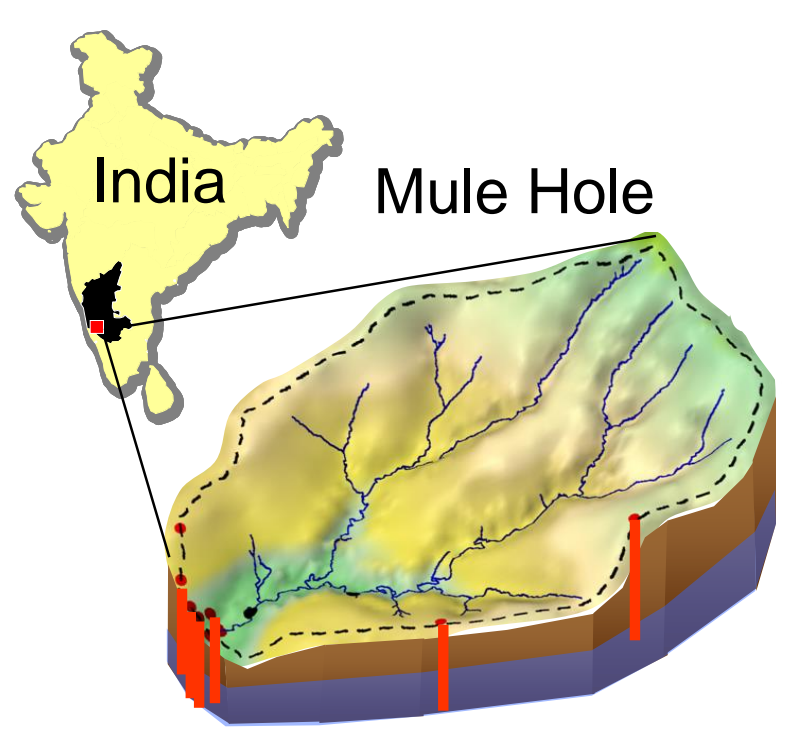

\section{Soil repartition}

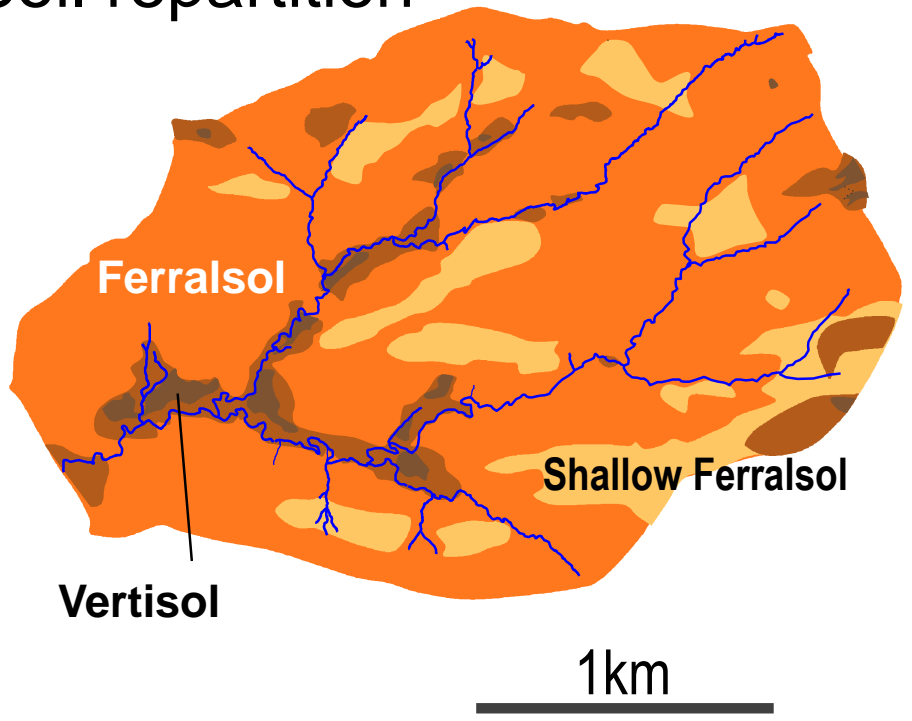

- Vertisol profile

- Ferralsol profile

$\triangle$ Overland flow
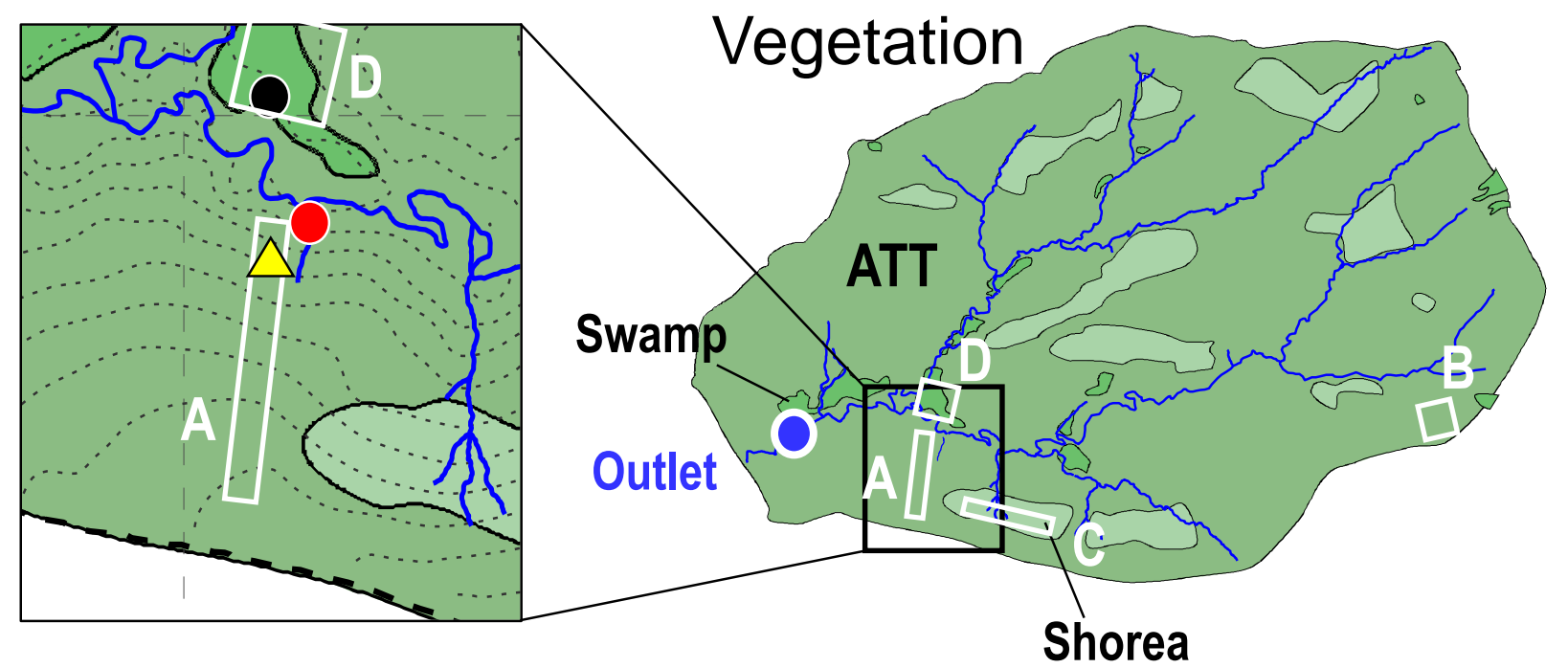


\section{Figure 2}

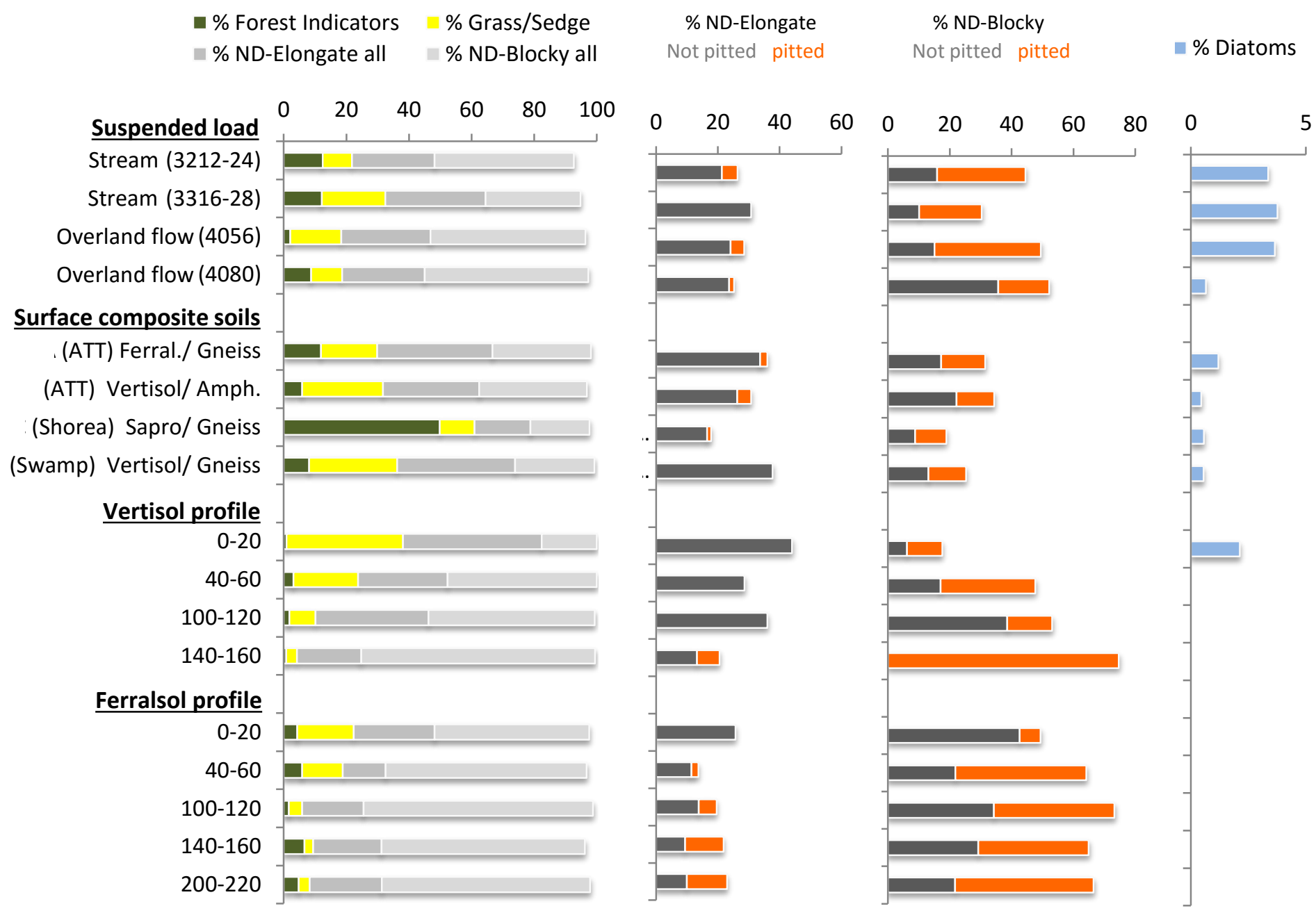




\section{Figure 3}

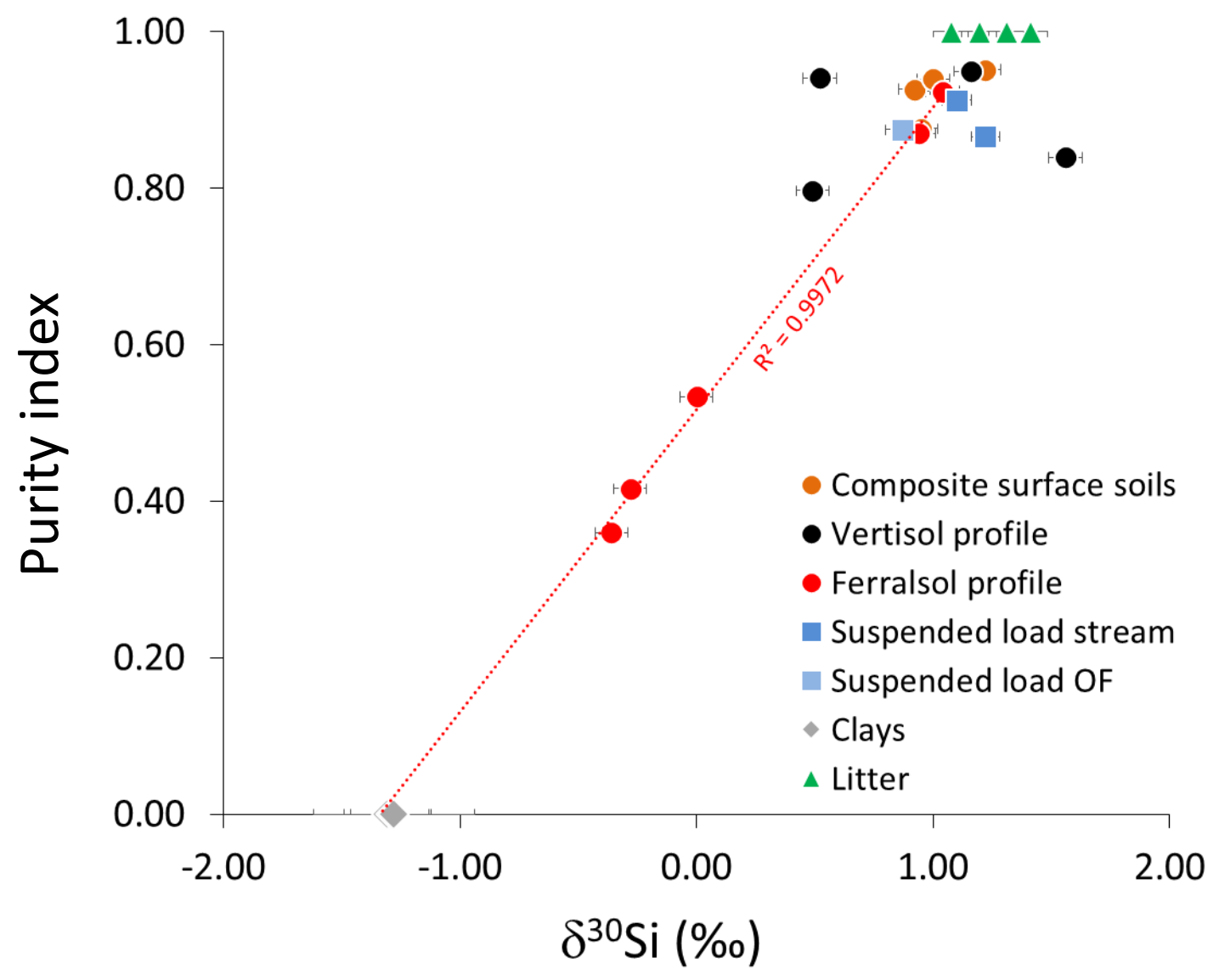


Figure 4

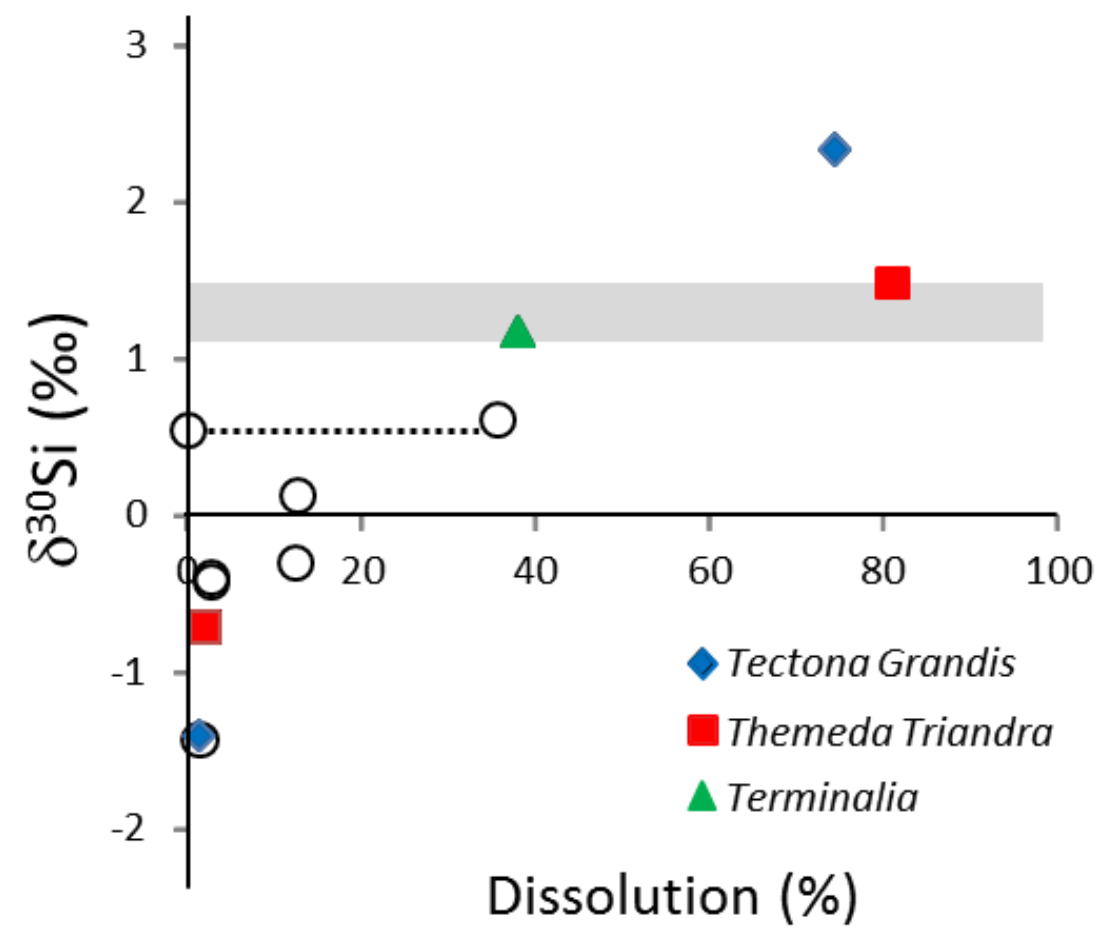




\section{Figure 5}

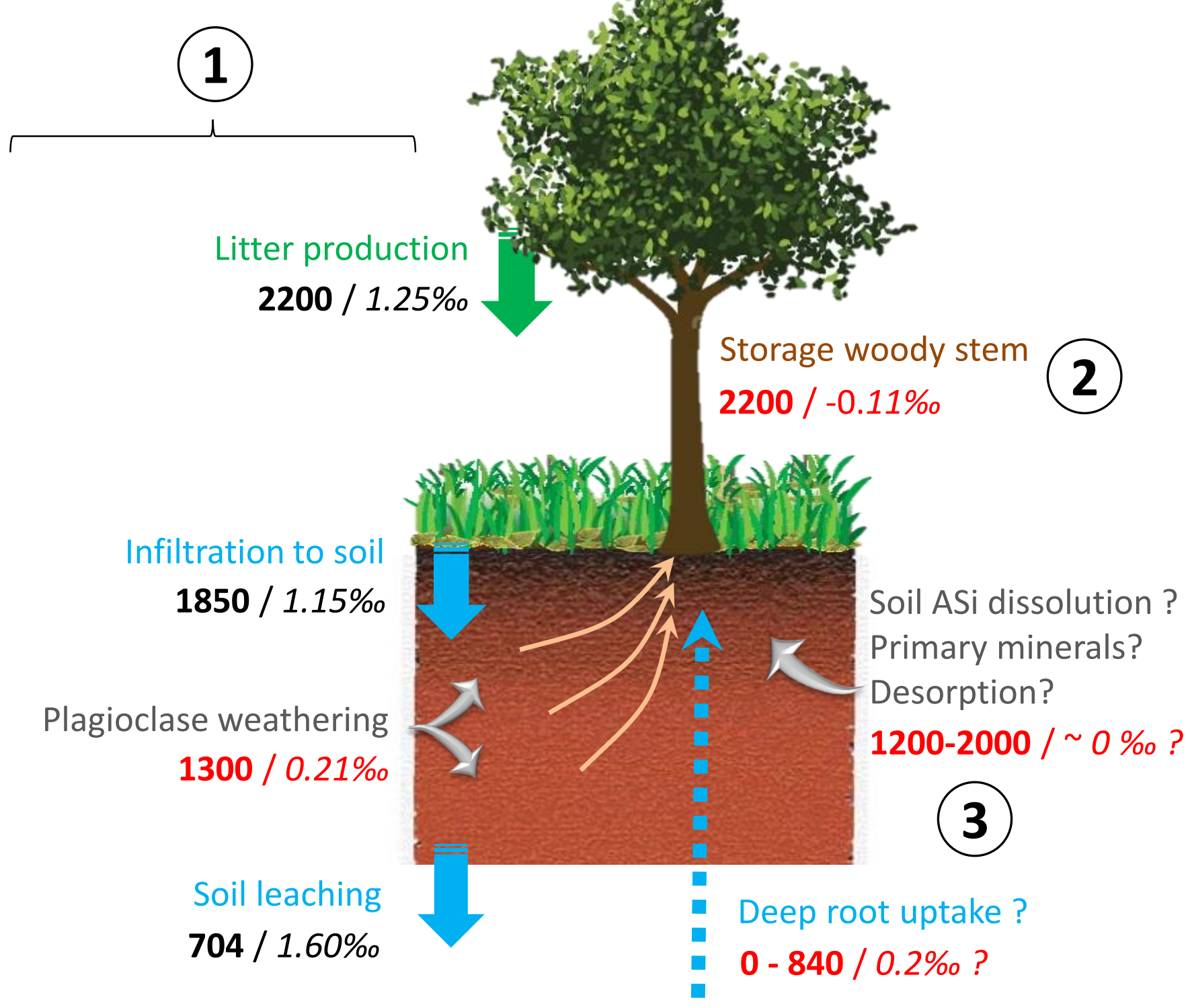




\section{Figure 6}

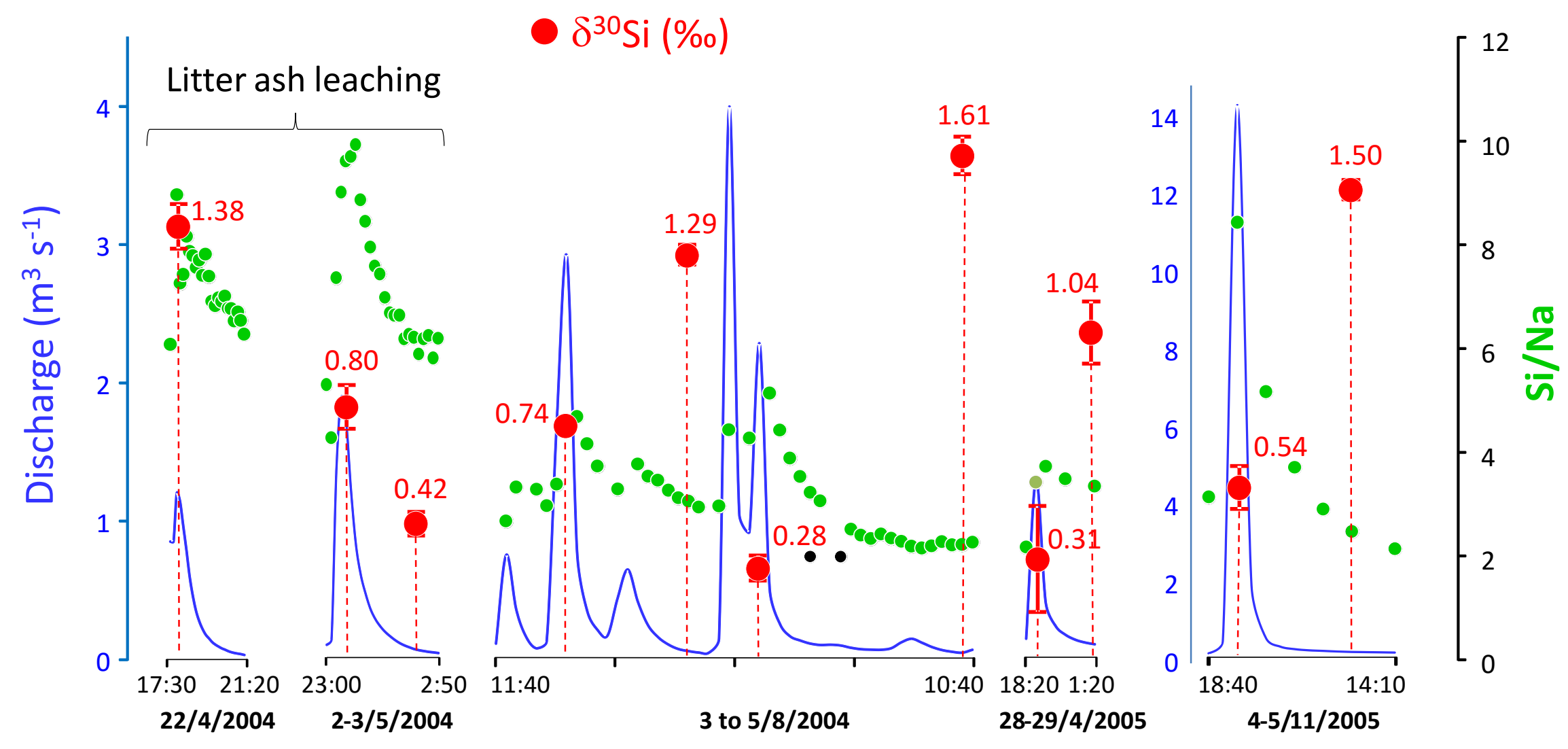


Table 1 : Repartition of primary and secondary Si pools in ferralsol and vertisol profiles of the Mule Hole watershed, with $\delta^{30} \mathrm{Si}$ of the ferralsol profile (bulk and clay fractions). "\% Si" refers to the percentage of total Si in a given pool.

\begin{tabular}{|c|c|c|c|c|c|c|c|c|c|}
\hline & $\begin{array}{c}\delta^{30} \mathrm{Si} \\
\% \text { \% }\end{array}$ & $\begin{array}{l}2 \sigma \\
\%\end{array}$ & $\begin{array}{c}\text { n clay content } \\
\%<2 \mu \mathrm{m}\end{array}$ & $\begin{array}{c}\% \mathbf{S i} \\
<2 \mu \mathrm{m}\left({ }^{*}\right) \\
\end{array}$ & $\begin{array}{c}\delta^{30} \mathrm{Si} \text { in }<2 \mu \mathrm{m} \\
\% \text { o }\end{array}$ & $\begin{array}{l}2 \sigma \\
\% \circ\end{array}$ & $\begin{array}{c}\% \mathrm{Si} \\
\text { clays }(* *)\end{array}$ & $\begin{array}{c}\% \mathrm{Si} \\
\text { prim. } \min .(* * *) \\
\end{array}$ & $\begin{array}{c}\% \mathrm{Si} \\
\text { quartz (\#) }\end{array}$ \\
\hline Fresh gneiss & -0.34 & 0.08 & 3 & & & & & & \\
\hline \multicolumn{10}{|l|}{ Ferralsol profile } \\
\hline $0-20 \mathrm{~cm}$ & -0.26 & 0.08 & 38 & 8 & -1.29 & 0.16 & 9 & 88 & 79 \\
\hline $40-60 \mathrm{~cm}$ & -0.30 & 0.11 & 43 & 9 & -1.33 & 0.06 & 10 & 87 & 77 \\
\hline $100-120 \mathrm{~cm}$ & -0.42 & 0.27 & 51 & 11 & -1.28 & 0.34 & 12 & 86 & 76 \\
\hline $140-160 \mathrm{~cm}$ & & & 48 & 10 & & & 12 & 87 & 77 \\
\hline $200-220 \mathrm{~cm}$ & & & 42 & 9 & & & 10 & 89 & 78 \\
\hline STOCK $(\mathrm{kg} / \mathrm{m} 2)$ & & & & 330 & & & & 3049 & \\
\hline \multicolumn{10}{|l|}{ Vertisol profile } \\
\hline $0-20 \mathrm{~cm}$ & & & 21 & 4 & & & 5 & 95 & 75 \\
\hline $40-60 \mathrm{~cm}$ & & & 42 & 9 & & & 10 & 90 & 73 \\
\hline $100-120 \mathrm{~cm}$ & & & 49 & 10 & & & 12 & 89 & 71 \\
\hline $140-160 \mathrm{~cm}$ & & & 53 & 11 & & & 13 & 88 & 70 \\
\hline STOCK $(\mathrm{kg} / \mathrm{m} 2)$ & & & & 278 & & & & 2764 & \\
\hline
\end{tabular}

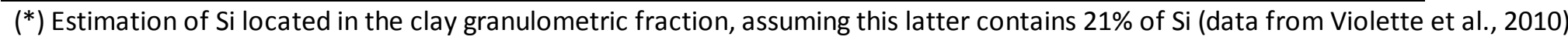

$\left.{ }^{* *}\right)$ Estimation of Si located in clays from the chemical composition of the soil, assuming $\mathrm{Na}$ is located in $\mathrm{Na}$-plagioclase,

$\mathrm{K}$ in sericite and $\mathrm{Al}$ in Na-plagioclase, sericite and clays and $\mathrm{Al}_{\mathrm{clay}}=\mathrm{Al}_{\text {total }}-\mathrm{Al}_{\text {sericite }}-\mathrm{Al}_{\mathrm{Na} \text {-plagioclase }}$

$(* * *) \mathrm{Si}_{\text {prim.min. }}=\left(\mathrm{Si}_{\text {total }}-\mathrm{Si}_{\text {clays }}-\mathrm{ASi}\right) / \mathrm{Si}_{\text {total }}$

(\#) : $\mathrm{Si}_{\text {quartz }}=S \mathrm{Si}_{\text {prim.min. }}-\mathrm{Si}_{\text {sericite }}-\mathrm{Si}_{\text {Na-plagioclase }}$ 
Table 2: ASi contents, chemical composition and $\delta^{30} \mathrm{Si}$ of the ASi fraction in the soils and suspended matter of Mule Hole and $\delta^{30} \mathrm{Si}$ of the litter.

\begin{tabular}{|c|c|c|c|c|c|c|c|c|c|c|c|c|c|}
\hline \multirow{2}{*}{$\begin{array}{l}\text { Sample } \\
\text { soil and suspended load }\end{array}$} & \multirow{2}{*}{$\begin{array}{c}\text { ASi } \\
\operatorname{raw}(\text { wt \%) }\end{array}$} & \multicolumn{6}{|c|}{ ASi composition (\%) } & purity index & \multirow{2}{*}{$\begin{array}{c}\text { ASi } \\
\text { corrected (\%) }\end{array}$} & \multirow{2}{*}{$\begin{array}{c}\delta^{30} \mathrm{Si} \\
\operatorname{raw}(\%)\end{array}$} & \multirow[t]{2}{*}{$2 \sigma$} & & \multirow{2}{*}{$\begin{array}{c}\delta^{30} \mathrm{Si}\left({ }^{* *}\right) \\
\text { corrected (\%) }\end{array}$} \\
\hline & & Si & Al & $\mathrm{Fe}$ & $\mathrm{Ca}$ & $\mathrm{Mg}$ & K & $\left({ }^{*}\right)$ & & & & & \\
\hline composite Ferralsol on gneiss $(0-15 \mathrm{~cm})$ & 0.36 & 37 & 3.1 & 1.6 & 0.0 & 0.1 & 0.5 & 0.88 & 0.32 & 0.95 & 0.05 & 5 & 1.25 \\
\hline composite Vertisol on amphibolite $(0-15 \mathrm{~cm})$ & 0.58 & 40 & 1.3 & 1.4 & 0.0 & 0.5 & 0.4 & 0.93 & 0.54 & 0.92 & 0.05 & 5 & 1.10 \\
\hline composite shallow Ferralsol on gneiss $(0-15 \mathrm{~cm})$ & 0.45 & 45 & 1.9 & 0.5 & 0.0 & 0.0 & 0.6 & 0.94 & 0.42 & 1.00 & 0.05 & 5 & 1.15 \\
\hline composite Vertisol on gneiss $(0-15 \mathrm{~cm})$ & $0.55(\dagger)$ & 48 & 1.5 & 0.6 & 0.1 & 0.1 & 0.5 & 0.95 & 0.52 & 1.22 & 0.04 & 5 & 1.30 \\
\hline Vertisol $(0-20 \mathrm{~cm})$ & $0.86(\dagger)$ & 40 & 1.2 & 0.3 & 0.2 & 0.1 & 0.4 & 0.95 & 0.82 & 1.16 & 0.04 & 5 & 1.26 \\
\hline Vertisol $(40-60 \mathrm{~cm})$ & $0.42(+)$ & 49 & 2.1 & 0.3 & 0.3 & 0.1 & 0.5 & 0.94 & 0.40 & 0.52 & 0.06 & 5 & 0.63 \\
\hline Vertisol $(100-120 \mathrm{~cm})$ & $0.06(+)$ & 37 & 5.0 & 2.0 & 0.3 & 0.4 & 0.9 & 0.80 & 0.05 & 0.49 & 0.03 & 5 & 0.96 \\
\hline Vertisol $(140-160 \mathrm{~cm})$ & $0.14(+)$ & 28 & 2.9 & 1.8 & 0.1 & 0.2 & 0.5 & 0.84 & 0.12 & 1.56 & 0.06 & 5 & 2.10 \\
\hline Ferralsol $(0-20 \mathrm{~cm})$ & $0.24(+)$ & 33 & 2.9 & 1.3 & 0.0 & 0.0 & 0.6 & 0.87 & 0.21 & 0.94 & 0.02 & 5 & 1.25 \\
\hline Ferralsol $(40-60 \mathrm{~cm})$ & 0.17 & 35 & 1.8 & 0.8 & 0.0 & 0.0 & 0.6 & 0.92 & 0.16 & 1.04 & 0.05 & 5 & 1.25 \\
\hline Ferralsol $(100-120 \mathrm{~cm})$ & 0.11 & 23 & 10.4 & 6.0 & 0.0 & 0.3 & 1.1 & 0.36 & 0.04 & -0.36 & 0.03 & 5 & 1.25 \\
\hline Ferralsol $(140-160 \mathrm{~cm})$ & 0.12 & 26 & 8.3 & 4.9 & 0.0 & 0.2 & 1.1 & 0.54 & 0.06 & 0.00 & 0.05 & 5 & 1.25 \\
\hline Ferralsol $(200-220 \mathrm{~cm})$ & 0.05 & 24 & 9.6 & 5.4 & 0.0 & 0.2 & 1.1 & 0.42 & 0.02 & -0.28 & 0.03 & 5 & 1.25 \\
\hline Suspended matter stream 3212-3224 & 0.52 & 36 & 2.1 & 1.0 & 0.1 & 0.1 & 0.4 & 0.91 & 0.48 & 1.10 & 0.02 & 3 & 1.30 \\
\hline Suspended matter stream 3316-3328 & 0.37 & 36 & 3.2 & 1.5 & 0.1 & 0.2 & 0.6 & 0.87 & 0.32 & 1.22 & 0.03 & 3 & 1.60 \\
\hline Suspended matter overlandflow 4056 & 0.12 & 39 & 3.3 & 1.5 & 0.0 & 0.0 & 0.9 & 0.88 & 0.11 & 0.87 & 0.07 & 3 & 1.16 \\
\hline \multicolumn{14}{|l|}{ litter } \\
\hline Themeda Triandra (from phytoliths) & & & & & & & & & & 1.31 & 0.16 & 3 & \\
\hline Themeda Triandra (from total digestion) & & & & & & & & & & 1.08 & 0.11 & 3 & \\
\hline Terminalia Alata (from total digestion) & & & & & & & & & & 1.41 & 0.02 & 3 & \\
\hline Tectona Grandis (from total digestion) & & & & & & & & & & 1.19 & 0.09 & 3 & \\
\hline
\end{tabular}

$\left(^{*}\right)$ ASi purity $=(\mathrm{Si}-(\mathrm{Al}+\mathrm{Fe}+\mathrm{Ca}+\mathrm{Mg}+\mathrm{Mn}+\mathrm{K})) / \mathrm{Si}$

$\left({ }^{* *}\right)$ considering a binary mixture with the clay composition as the impurity end-member and projection to purity index of 1 .

$(\dagger)$ data from Meunier et al. (2014) 
Table 3 : Silica content and $\delta^{30} \mathrm{Si}$ in the water compartments of Mule Hole.

\begin{tabular}{|c|c|c|c|c|c|c|}
\hline & sampling date & $\begin{array}{c}\text { discharge } \\
\mathrm{m}^{3} / \mathrm{s}\end{array}$ & $\begin{array}{c}\mathbf{S i} \\
\mu \mathrm{mol} / \mathrm{L}\end{array}$ & $\begin{array}{c}\delta^{30} \mathrm{Si} \\
\%\end{array}$ & $\begin{array}{l}2 \sigma \\
\%\end{array}$ & $\bar{n}$ \\
\hline \multicolumn{7}{|l|}{ Stream } \\
\hline 2004SS1 & 22/4/04 17:50 & 1.20 & 270 & 1.38 & 0.07 & 5 \\
\hline 2004SS2 & 2/5/04 23:40 & 1.72 & 238 & 0.80 & 0.07 & 5 \\
\hline 2004SS2 & $3 / 5 / 042: 10$ & 0.06 & 152 & 0.42 & 0.04 & 5 \\
\hline 2004SS5 & 3/8/04 18:40 & 2.90 & 160 & 0.74 & 0.02 & 5 \\
\hline 2004SS5 & 4/8/04 5:40 & 0.06 & 216 & 1.29 & 0.03 & 3 \\
\hline 2004SS5 & 4/8/04 13:40 & 2.27 & 142 & 0.28 & 0.04 & 3 \\
\hline 2004SS5 & 5/8/04 9:40 & 0.03 & 258 & 1.61 & 0.06 & 5 \\
\hline 2005SS2 & 28/4/05 19:21 & 1.28 & 78 & 0.31 & 0.17 & 5 \\
\hline 2005SS2 & 29/4/05 1:21 & 0.09 & 97 & 1.04 & 0.10 & 5 \\
\hline 2005SS19 & 4/11/05 21:40 & 14.2 & 135 & 0.54 & 0.07 & 3 \\
\hline 2005SS19 & 5/11/05 9:40 & 0.14 & 293 & 1.50 & 0.03 & 5 \\
\hline \multicolumn{7}{|l|}{ Overland flow } \\
\hline on Ferralsol & 02/09/09 & & 193 & 1.03 & 0.06 & 5 \\
\hline on Ferralsol & 05/10/09 & & 164 & 1.16 & 0.07 & 5 \\
\hline on Ferralsol & $11 / 11 / 09$ & & 184 & 0.99 & 0.09 & 5 \\
\hline on Verti./Ferral. Trans. & 02/09/09 & & 246 & 2.22 & 0.69 & 3 \\
\hline on Verti./Ferral. Trans. & 16/10/09 & & 223 & 0.96 & 0.06 & 3 \\
\hline on Verti./Ferral. Trans. & $21 / 11 / 09$ & & 166 & 1.23 & 0.15 & 3 \\
\hline on Verti./Ferral. Trans. & $11 / 11 / 09$ & & 195 & 0.44 & 0.16 & 3 \\
\hline \multicolumn{7}{|l|}{ Soil porewater } \\
\hline Vertisol 1 & $15 / 06 / 04$ & & 368 & 1.92 & 0.06 & 5 \\
\hline Vertisol 2 & $15 / 06 / 04$ & & 405 & 1.71 & 0.10 & 5 \\
\hline Vertisol 3 & $15 / 06 / 04$ & & 508 & 1.61 & 0.04 & 5 \\
\hline Vertisol 4 & $15 / 06 / 04$ & & 508 & 1.73 & 0.06 & 5 \\
\hline Vertisol 5 & 23/07/09 & & 447 & 1.46 & 0.12 & 3 \\
\hline Verti./Ferral. Trans. & $30 / 11 / 10$ & & 451 & 1.73 & 0.04 & 4 \\
\hline Verti./Ferral. Trans. & $23-24 / 7 / 9$ & & 382 & 1.61 & 0.07 & 5 \\
\hline Verti./Ferral. Trans. & 23/07/09 & & 401 & 1.45 & 0.04 & 5 \\
\hline Verti./Ferral. Trans. & $30 / 11 / 10$ & & 488 & 1.58 & 0.08 & 5 \\
\hline Groundwater & & depth (m) & & & & \\
\hline P3 & 23/10/05 & 27.75 & 849 & 0.81 & 0.06 & 5 \\
\hline P5 & 23/10/05 & 40.57 & 702 & 1.12 & 0.08 & 5 \\
\hline P6 & 23/10/05 & 38.47 & 526 & 1.33 & 0.06 & 5 \\
\hline $\mathrm{P} 13$ & 23/10/05 & 9.15 & 710 & 1.49 & 0.06 & 5 \\
\hline
\end{tabular}

